\title{
Contribution to Tumor Angiogenesis From Innate Immune Cells Within the Tumor Microenvironment: Implications for Immunotherapy
}

\author{
Adriana Albini ${ }^{1,2 *}$, Antonino Bruno ${ }^{1 \dagger}$, Douglas M. Noonan ${ }^{1,3 \neq}$ and Lorenzo Mortara ${ }^{3 \neq}$ \\ ${ }^{1}$ Scientific and Technology Pole, IRCCS MultiMedica, Milano, Italy, ${ }^{2}$ Department of Medicine and Surgery, University \\ Milano-Bicocca, Monza, Italy, ${ }^{3}$ Department of Biotechnology and Life Sciences, University of Insubria, Varese, Italy
}

\section{OPEN ACCESS}

Edited by:

Salem Chouaib, Institut Gustave

Roussy, France

Reviewed by:

Amorette Barber,

Longwood University,

United States

Leticia Corrales,

Aduro BioTech, United States

*Correspondence:

Adriana Albini

albini.adriana@gmail.com

tThese authors have contributed equally to this work.

*These authors share senior authorship.

\section{Specialty section: \\ This article was submitted to \\ Cancer Immunity and Immunotherapy, \\ a section of the journal \\ Frontiers in Immunology}

Received: 21 December 2017

Accepted: 28 February 2018

Published: 05 April 2018

Citation:

Albini A, Bruno A, Noonan DM and Mortara L (2018) Contribution to Tumor Angiogenesis From Innate

Immune Cells Within

the Tumor Microenvironment: Implications for Immunotherapy.

Front. Immunol. 9:527. doi: 10.3389/fimmu.2018.00527
The critical role of angiogenesis in promoting tumor growth and metastasis is strongly established. However, tumors show considerable variation in angiogenic characteristics and in their sensitivity to antiangiogenic therapy. Tumor angiogenesis involves not only cancer cells but also various tumor-associated leukocytes (TALS) and stromal cells. TALs produce chemokines, cytokines, proteases, structural proteins, and microvescicles. Vascular endothelial growth factor (VEGF) and inflammatory chemokines are not only major proangiogenic factors but are also immune modulators, which increase angiogenesis and lead to immune suppression. In our review, we discuss the regulation of angiogenesis by innate immune cells in the tumor microenvironment, specific features, and roles of major players: macrophages, neutrophils, myeloid-derived suppressor and dendritic cells, mast cells, $\gamma \delta T$ cells, innate lymphoid cells, and natural killer cells. Anti-VEGF or anti-inflammatory drugs could balance an immunosuppressive microenvironment to an immune permissive one. Anti-VEGF as well as anti-inflammatory drugs could therefore represent partners for combinations with immune checkpoint inhibitors, enhancing the effects of immune therapy.

\section{Keywords: angiogenesis, chemoprevention, tumor microenvironment, immune cells, immunotherapy}

\section{INTRODUCTION}

The "gradient" of phenotype, genetic, and epigenetic features of transformed cells inside the tumor gives rise to the most known and studied tumor heterogeneity, the "intrinsic" one. However, increasing attention is devoted to "extrinsic" heterogeneity, i.e., all those cellular and molecular "players" that include the non-cancerous hosting environment. Cancers develop in complex tissue environments, both in the primary and in the target organs of metastasis. A "hostile" setting is elicited, such as low oxygen, acidity, and altered metabolic conditions. Cancer cells adapt more rapidly than healthy ones to the adverse conditions that paradoxically sustain growth, invasion, and metastasis. In such an "infernal" environment, interactions between tumor cells and the associated stroma represent a dangerous relationship that reciprocally influences disease initiation, progression and, in the end, determines patient prognosis (1).

The confirmed theory that the presence of inflammatory cells plays a crucial role within the tumor microenvironment (TME) is a very old one (2). "Evading immune destruction" and "tumorpromoting inflammation" are recognized host-dependent tumor hallmarks as defined by Hanahan and Weinberg (3). Among the tumor-friendly phenomena generated through the activity of the 
inflammatory cells in the microenvironment, there is the orchestration of angiogenesis, a biological phenomenon necessary to bring oxygen, nutrition to the tumors, and last but not least, to transport the cancer cell to metastatic sites (4-7). Innate immune cells, as a consequence of their plasticity, have been reported to acquire an altered phenotype that can be proangiogenic. For many immune cells, both from innate and adaptive immunity, the release of proangiogenic cytokines is accompanied by a switch to a tolerogenic/immunosuppressive behavior (4, 7-9). In this review, we choose to describe the role in angiogenesis of selected major classes of inflammatory cells: macrophages, neutrophils, myeloid-derived suppressor cells (MDSCs), dendritic cells (DCs), mast cells (MCs), gammadelta $(\gamma \delta)$ T type 17 cells $(\gamma \delta \mathrm{T} 17)$, innate lymphoid cells (ILCs), and natural killer (NK) cells (Figure 1). We also sustain the rationale behind using antiangiogenic drugs before the onset of immunotherapy and we propose as an innovative, low-cost strategy the use of "repurposed" anti-inflammatory/ chemopreventive drugs to assist immunotherapies.

\section{MACROPHAGES}

Macrophages constitute professional phagocytes of the innate immune cell compartment with different specialized functions, depending on the type of danger signals and endogenous molecules to which they are exposed (10). They act as sentinels in all tissues of the body against invading pathogens, are able to

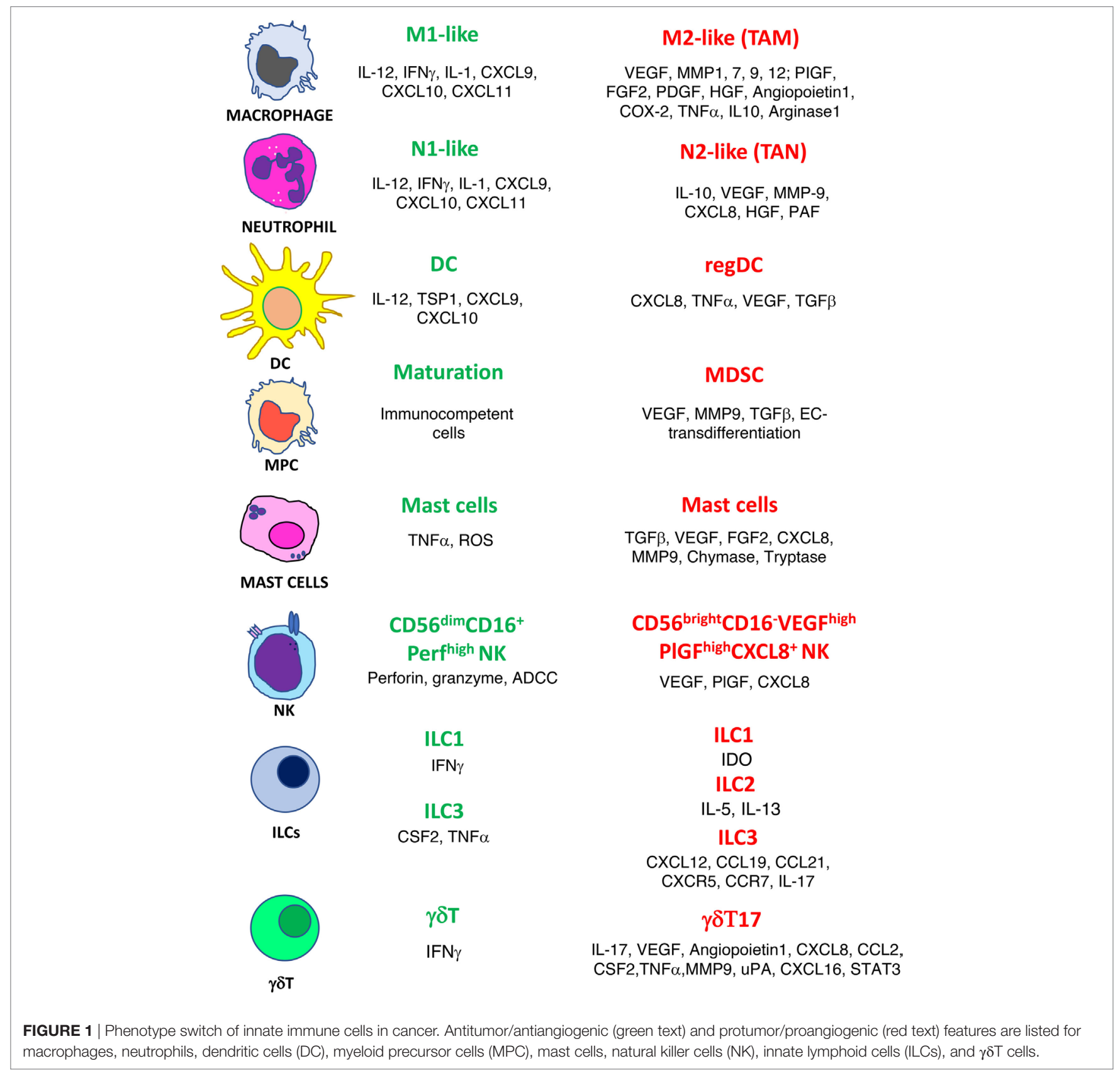


trigger an inflammatory response, and collaborate with other immune cells to activate adaptive $\mathrm{T}$ lymphocyte responses through antigen processing and presentation. These activities are related to a classical activation state, which is type $1 \mathrm{~T}$ helper (TH1) cell associated and INFy and/or LPS-dependent, and is referred to as M1. This condition is favorable to immune response. Macrophages can be alternatively activated by IL- 4 and/ or IL-13 signals from TH2 cells, eosinophils, and/or basophils in the surrounding microenvironment. This polarization is involved in parasite control and wound healing and is termed M2 (11). M2 macrophages are associated with chemical and physical tissue damage in which they mediate tissue homeostasis and repair via remodeling and angiogenesis, in a spectrum of differentiation states. In vivo, the plasticity and diversity of macrophages are responsible of a spectrum of different activation states strictly depending on an array of concordant but also discordant stimuli, such as hypoxia, chemokines, colony-stimulating factor 1 (CSF1), TGF $\beta$, adenosine, and prostaglandin E2 (PGE2), that do not fit with the M1/M2 classification (12). For these reasons, M1-like is the preferred term used in this review and indicate a polarization state of macrophages that are able to orchestrate cytotoxic antipathogen and antitumor responses, whereas M2-like are cells that have the common functional feature of favoring tumor cell fitness, new blood vessel formation, as well as suppressive activities toward adaptive immune cells $(13,14)$. Tumor-associated macrophages (TAMs), which share many features with M2-like macrophages (Figure 2), represent the major cell population of tumor-infiltrating leukocytes (15). TAMs also show consistent differences between diverse types of cancers $(16,17)$. Elevated TAM infiltration has been correlated with poor clinical outcome in many types of cancers, such as ovarian, breast, prostate, cervical, and thyroid cancers, Hodgkin's lymphoma, cutaneous melanoma, lung, and hepatocellular carcinomas (14, 18-22). Conversely, other reports on colorectal, prostatic, and lung cancers have detected a positive role of infiltrating macrophages favoring increased patient survival (23-25). During cancer development, macrophages are recruited in the tumor stroma by several inflammatory mediators, such as chemokines: CCL2 (also known as MCP-1), CCL5, CXCL12 (also known as SDF-1), cytokines: vascular endothelial growth factor (VEGF), CSF1, and activated complement elements. Blood monocytes, blood monocytic MDSCs, cells, or tissue-resident macrophages (26-28) are subverted in their phenotype and functions to differentiate into TAMs (14). However, TAMs are not fixed in an irreversible

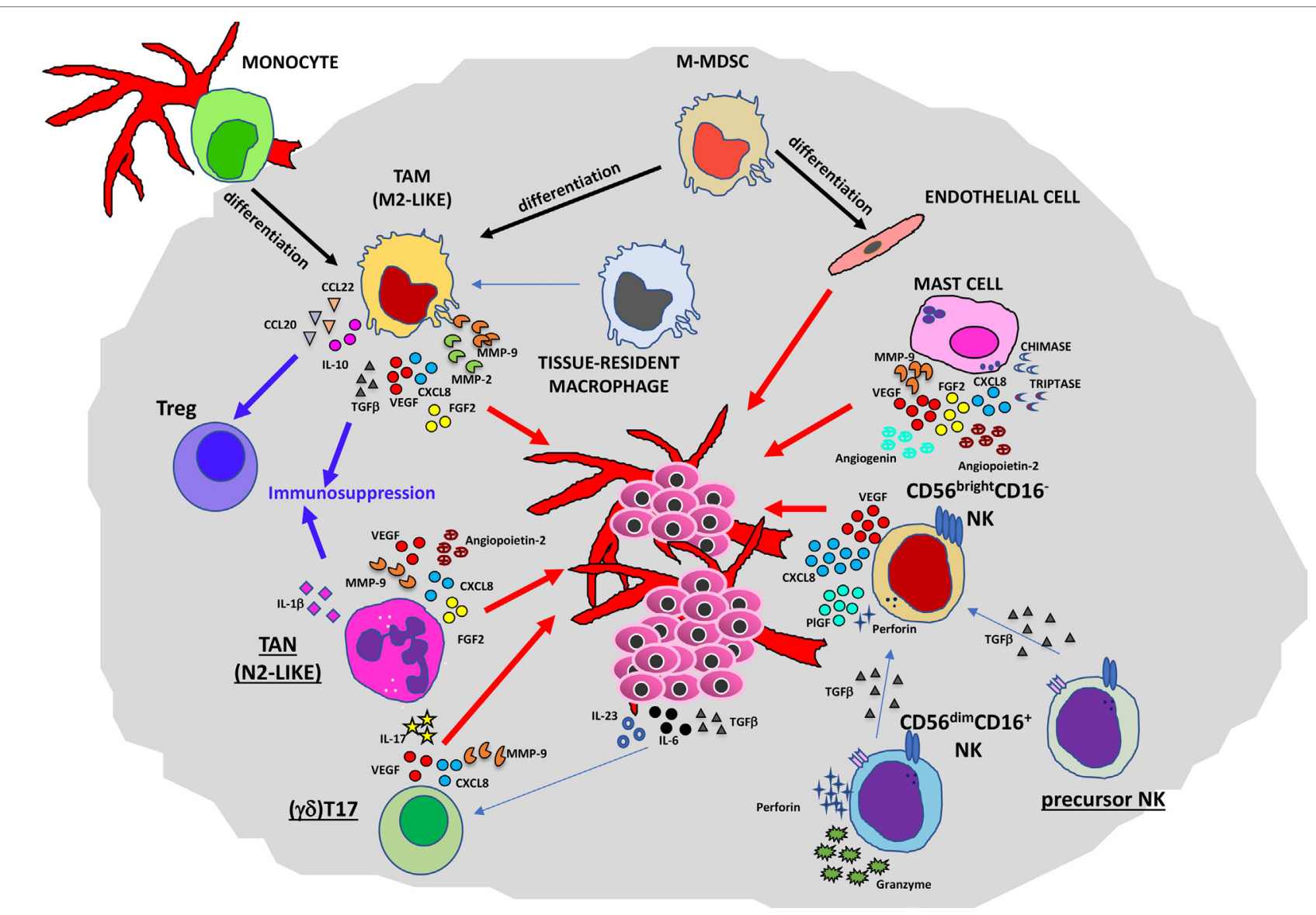

FIGURE 2 | Contribution of innate immunity to tumor angiogenesis. Soluble mediators (chemokines, cytokines, and enzymes) within the tumor microenvironment act directly or indirectly as proangiogenic factors produced by macrophages [M2-like tumor-associated macrophages (TAMs)], neutrophils [tumor-associated neutrophil (TAN), N2-like], myeloid-derived-suppressor cells (MDSCs), mast cells, and natural killer (NK) cells. 
phenotype, they maintain their plasticity and eventually could be targeted by specific therapeutic approaches to re-educate them to M1-like antitumor functions (29). Accumulating evidence have shown that TAMs can act as key cellular mediators, interconnecting chronic inflammation with cancer development and progression $(3,30)$.

Several lines of research have pointed out the role of TAMs in the regulation of tumor cell invasion, angiogenesis, lymphangiogenesis, and metastasis $(11,19)$. In primary tumors (Figure 2), they can promote angiogenesis (the "angiogenic switch") triggering the activation and the recruitment of endothelial cells (ECs), essentially by producing multiple proangiogenic factors, including VEGFA, epidermal growth factor (EGF), basic fibroblast growth factor 2 (FGF2), chemokines CXCL8 (also known as IL-8), CXCL12, TNF $\alpha$, semaphorin $4 \mathrm{D}$, adrenomedullin, and thymidine phosphorylase (31-34). These factors produced by TAMs are responsible for the proliferation of ECs and the induction of sprouting, tube formation, and maturation of new vessels. Macrophages have been shown to play a critical role in tumor lymphangiogenesis by producing VEGFC and VEGFD (35-37). TAM activities can also have an impact on degradation and remodeling of the extracellular matrix (ECM), through the production of different classes of enzymes and proteases, such as matrix metalloproteinases (MMPs in particular MMP2 and MMP9), plasmin, urokinase plasminogen activator (uPA), and cathepsins, thereby influencing tumor invasion and the metastatic process (38-40).

Tumor-associated macrophages are also associated with resistance to different chemotherapeutic agents, involving the activation of distinct molecular pathways. In breast cancers, TAMs are able to inhibit apoptosis of cancer cells upon paclitaxel treatment via induction of IL-10/signal transducer and activator of transcription (STAT)3/Bcl-2 signaling (41). In patients with non-small cell lung cancer, TAMs or M2-like TAMs dampen the responsiveness to targeted therapy with EGF receptor-tyrosine kinase inhibitors $(42,43)$.

A highly proangiogenic M2-like TAM subset is represented by angiopoietin responsive Tie $2^{+}$perivascular macrophages (35-37), which are able to induce chemotherapeutic drug resistance, favoring decreasing cancer cell responsiveness to radiotherapy (44). Specific inhibition of the angiopoietin/Tie2 axis can act in synergy with antiangiogenic treatments (45). Apart from their proangiogenic features, TAMs also play a crucial role in promoting an immunosuppressive milieu helping different tumors to escape immunosurveillance (46). Their contribution to tumor progression act also through crosstalk with other leukocytes and inflammatory and stromal cells $(7,47)$ within the TME. In the establishment of the immunosuppressive milieu, TAMs can directly recruit T regulatory (Treg) cells, by producing CCL20 (48) and CCL22 chemokines (49) and can activate them by secreting IL-10 and TGF $\beta$ (26). TAMs also represent an important factor for the establishment of the premetastatic niche $(50,51)$.

Different TAM-targeted therapeutic strategies have been developed with the aim to inhibit macrophage recruitment, to induce cell death, and to re-educate killer functions. These innovative therapeutic approaches could behave as a complement strategy in combination with antiangiogenic, cytoreductive, and/ or immune checkpoint inhibitor treatments, and preclinical and clinical trial results are promising (14, 30, 52). CCL2-specific inhibition by antibodies has proven efficacious in mouse models of prostate, breast, lung, and melanoma, and this approach was synergistic with chemotherapy $(53,54)$. Different antibodies targeting CCL2 have entered phase I and II clinical trials (55). A CCR5 antagonist has been approved for the treatment of patients with liver metastases from advanced colorectal cancers and experimental data indicate that CCL5/CCR5 axis targeting could be suitable for clinical responses (56). Diverse compounds and antibody inhibitors that have been developed to inhibit the CSF1-CSF1R axis, could target TAM, and were evaluated in mouse models and in patients with different types of cancer (57). In diffuse-type tenosynovial giant-cell tumor showing overexpression of CSF1R, after treatment with CSF1R-blocking agents, patients experienced relevant clinical regressions $(57,58)$. In preclinical glioblastoma multiforme model, CSF1R blockade did not affect the TAM numbers but the M2-like TAM polarization markers were lowered, thus was associated with improvement of survival (59). Bisphosphonates, that are used to treat osteoporosis and to prevent bone metastases-related complications, can also be used to target macrophages inside the tumor (60). Moreover, bisphosphonates in combination with chemotherapy or hormonal therapy have been shown clinical synergistic effects, in different types of cancer patients, in particular for patients with breast cancer (61). In a murine model of pancreatic ductal adenocarcinoma (PDAC), the anti-CD40- and gemcitabine-treated mice induced re-education of M2-like TAM toward an M1-like macrophage and elicit effective antitumor responses (62). This lead to a phase I clinical trial in PDAC patients, the combination was well tolerated and provided some antitumor efficacy (63). A recently identified potent compound that targets TAMs is trabectedin, a synthetic form of a molecule isolated from the marine tunicate Ecteinascidia turbinata, which has found application in the treatment of soft tissue sarcomas and ovarian cancer patients. Trabectedin induces selective TRAIL-dependent apoptosis of monocytes, macrophages, and the monocytic component of MDSCs in blood, spleen, and tumors with the reduction of TAM numbers and angiogenesis $(64,65)$.

\section{NEUTROPHILS}

Neutrophils are the most abundant innate immune cells in the peripheral blood, they act as a first line of defense against invading pathogens and are crucial effectors in the acute phase of inflammation. Neutrophils are recruited in the damaged area by chemokines, in particular CXCL8, and the cognate receptors CXCR1 and CXCR2 (66). These leukocytes exert important functions such as phagocytosis, production and release of antimicrobial ROS, peptides, enzymes, and neutrophil extracellular traps (NET). Neutrophils can release a substantial quantity of different reactive soluble factors, including cytokines and chemokines (67), and are able to recruit and activate other immune cells, playing an important role in the regulation of chronic inflammation, tumor angiogenesis, and progression. Inflammatory $\mathrm{CD} 6 \mathrm{~b}^{+}$neutrophils can be found in high numbers in either blood or TME of different cancers and correlated with poor clinical outcome (68-74). 
Neutrophils produce either proangiogenic or antiangiogenic factors (75-79), and in some cases, such as in the early phases of lung cancers, they can exert important T cell stimulatory, antitumor functions (80). Although they are characterized by a terminally differentiated phenotype and a short half-life, these cells are endowed with a certain kind of plasticity and in murine tumor models they are able to differentiate in two distinct subsets: neutrophils type 1 (N1) with antimicrobial functions, and tumorassociated neutrophils (TANs or N2) endowed with protumor and proangiogenic features (Figure 2) in response to TGF $\beta$ (81, 82). In response to IFN $\beta$, TAN/N2 neutrophils can be converted to N1 type in both mouse lung cancers and human melanomas $(83,84)$.

Accumulating evidence has indicated TANs as key players involved in tumor angiogenesis and metastatic process in both mice and humans (Figure 2). The complex role of TANs in tumor angiogenesis and metastasis resides mainly in the capacity of these cells to secrete an array of diverse immunosuppressive or proangiogeneic molecules such as IL-1 $\beta$, VEGF, FGF2, TGF $\alpha$, hepatocyte growth factor (HGF), and angiopoietin 1 (ANG1) different chemokines such as CXCL1, CXCL8, CXCL9, CXCL10, CCL3, and CCL4 (6) and enzymes involved in ECM remodeling (MMP9). Production and expansion of neutrophils is dependent on CSF3 (G-CSF) and its receptor CSF3R. A crucial signaling pathway for cancer inflammation is STAT3 (85), which is downstream of activated CSF3R. In response to CSF3, neutrophils upregulate the expression of BV8 (also known as prokineticin-2) that induce myeloid cell mobilization and myeloid-dependent tumor angiogenesis (86). This production of BV8 depends on the activation of STAT3 (87). The tumor angiogenesis stimulation in mice by TANs and other myeloid cells is regulated by STAT3 signaling and involves VEGFA, FGF2, and MMP9 (88). MMP9secreting neutrophils can directly contribute in the acceleration of tumorigenesis acting on skin premalignant epithelial cells in a mouse model (89). During the early stages of carcinogenesis, TANs can mediate the initial angiogenic switch in RIP1-Tag2 transgenic mice model of pancreatic neuroendocrine tumor. The MMP9-positive neutrophils were mainly found inside angiogenic islet dysplasia as well as in tumors (90). The neutrophil depletion by GR1 or Ly6G antibodies in both transgenic and tumor transplanted mice resulted in lower levels of VEGF/VEGF receptor (VEGFR) signaling and a delay of the angiogenic switch (90). TANs lack expression of tissue inhibitors of metalloproteinases (TIMP1), rendering neutrophil-derived MMP9 more potent as angiogenesis driver in the TME than cells which produce MMP9/ TIMP1 complexes (91). Neutrophils with antiangiogenic features have been reported to be able to release the endogenous angiogenesis inhibitor thrombospondin-1 in peroxisome proliferatoractivated receptor (PPAR) $\alpha$-deficient mice, thus preventing angiogenesis and tumor growth (92). These reports suggest that PPAR $\alpha$ is a central transcriptional suppressor of inflammation and tumor development and could be a valuable target. Group $\mathrm{V}$ secreted phospholipase A2 enzymes are released by human neutrophils and enhance the proangiogenic molecules VEGFA, ANG1, and CXCL8 in an autocrine mechanism (93), but also stimulate production of the antiangiogenic isoform of VEGFA, VEGFA $_{165 b}$ (94). The functional outcome probably depends on the balance between proangiogenic and antiangiogenic factors and is still matter of investigation.

The ability of neutrophils to release several proangiogenic factors, MMPs, and other proteases (95) and to trap cancer cells via NET secretion (96) could promote cancer metastasis. TANs are required for the development of the premetastatic niche and metastases in murine models (97-99).

Recently, new data have brought clarity on the role of TANs and TAMs in the resistance to antiangiogenic therapy. Tumors activate PI3K signaling in all CD11 $\mathrm{b}^{+}$cells (both neutrophils and monocytes) (100). Inhibition of one of these cell types induces a compensatory phenomenon by the other cell types, which overcomes the angiogenic blockade. Hindering PI3K in all CD11b myeloid cells generate a long-lasting angiostatic effect (100).

\section{IMMATURE MYELOID CELLS (MDSC AND DC)}

Immature myeloid cells are innate immunity cells that infiltrate the TME, having a critical role in the proangiogenic activities and in tumor immune evasion (Figure 1). The immature myeloid cells include MDSCs and DCs, also indicated as regulatory (reg) DCs $(101,102)$. The immature phenotype is due to constitutive activation of STAT3 that perturbs the differentiation process of these cells. MDSCs comprise in mice and humans two distinct immature myeloid cell types: the polymorphonuclear MDSC (PMN-MDSC) characterized by neutrophil features, and the monocytic MDSC (M-MDSC) having markers of monocytes. Recently, several articles have described exhaustively both MDSC and DC phenotypic characteristics and they will not be discussed here (103-105). Several tumor-derived factors, among which CSF3, IL-1 $\beta$, and IL-6, have been implicated in recruitment, activation, and expansion of MDSCs. These molecules contribute to the STAT3 activation of immature MDSCs, rendering them potent proangiogenic and immunosuppressive cells (106).

Monocytic MDSCs have been intensively studied and recognized as immunosuppressive cells as well as proangiogenic effectors in cancer (107). Murine data suggested that MDSCs are also able to differentiate into ECs $(108,109)$. Recent data have suggested that MDSCs in human peripheral lymphoid organs are mainly represented by PMN-MDSCs, with immunoregulatory role and are involved in the tumor-specific $\mathrm{T}$ cell tolerance. In the TME, there is accumulation of the M-MDSC counterpart, which is more suppressive and can rapidly differentiate to TAMs. These events might imply that targeting only one myeloid cell subset (macrophages vs. granulocytes or vice versa) may not be sufficient for obtaining a long-lasting immunotherapeutic effect. An investigation performed in two transplantable and two transgenic tumor murine models has shown that the tumor-induced hypoxia triggers the upregulation of CD45 tyrosine phosphatase activity in TME residing MDSCs, resulting in downregulation of STAT3 and differentiation of MDSCs into TAMs (106). There is no hypoxia in the spleens, thus CD45 downregulation of STAT3 does not occur in this organ. Use of STAT3 inhibitors in tumorbearing mice resulted in depletion of MDSCs in the spleen but not in tumors. 
Myeloid-derived suppressor cells and TAMs are regulated by metabolic constraints within the TME, and this represents a crucial factor of the signaling network regulating the expression of specific transcriptional programs with distinct protumor functions (110). Several amino acids in the TME are converted to immunomodulatory molecules such as nitric oxide, polyamines, and kinurenines. Amino acids consumption by myeloid cells decrease the availability of essential nutrients for T cells (111). The energetic metabolism of tumor-infiltrating MDCSs showed peculiar features in both mouse and human samples, such as a preferential augmented fatty acid uptake and their oxidation rather than glycolysis $(112,113)$. Targeting fatty acid oxidation inhibited tumor growth and combination with low dose chemotherapy blocked the MDSC immunosuppression (113). Myeloid cells in the TME produce increased fatty acid synthase in response to CSF1, which causes PPAR $\beta / \delta$-dependent expression of genes, like VEGF, IL-10, and arginase 1 (Arg1), involved in the proangiogenic and immunosuppressive responses (114). A promising therapeutic approach is based on the reprogramming and the re-education of the metabolism of MDSCs in the TME, with appropriate drugs in combination with immune checkpoint inhibitors (115).

Myeloid-derived suppressor cells are also characterized by the ability to express high amounts of NADPH oxidase, which is responsible for the production of ROS in the form of superoxide anion, hydrogen peroxide, and peroxynitrite. MDSCs present also an increased expression of Arg1 and of inducible forms of nitric oxide synthase 2 genes, and they release diverse inhibitory cytokines, contributing to the immunosuppressive effects in the TME (116).

Myeloid DCs, also known as conventional (c)DCs, consists of multiple cell subsets with potent antigen-presenting cell capacity, therefore playing a fundamental role in the activation of T-cell adaptive responses against pathogens and tumor cells. However, tumor-associated cDCs or regulatory DC (regDCs) in the TME display altered functions with impaired cross-presentation capacity, express low levels of co-stimulatory molecules, and have high-proangiogenic abilities. These changes depend on diverse conditions that are established during tumor progression, for example, hypoxia, production of PGE2, IL-10, adenosine, and increased levels of lactate (117-119).

One of the major mechanisms contributing to DC dysfunction in tumor-bearing animals and in patients with different cancers is the abnormal accumulation of lipids (120). Growing evidence shows that cDCs can drive either immunosurveillance or accelerated tumor progression depending on the environment. In both mouse and human ovarian cancers, CCR6 ${ }^{+} \mathrm{cDCs}$ are recruited massively in the TME through the tumor-derived $\beta$-defensins and are induced to become proangiogenic cells, favoring tumor vascularization, and growth in response of tumor VEGF (121).

Depleting DC numbers in the tumor-bearing host at early stages of the disease correlates with faster tumor development in a murine model of ovarian cancer. DC inhibition at advanced stages induces on the contrary significant delays in the malignant progression (122).

During tumor progression, the hypoxia-induced regDCs remain in an immature state and acquire tolerogenic immunosuppressive properties and proangiogenic activities, for instance, by secretion of galectin-1 $(123,124)$. Galectin 1 is able to bind VEGFR2 and neuropilin-1, mirroring the effect of VEGF on ECs, thereby promoting angiogenesis (123-125). Moreover, regDCs are involved in the expansion and activation of Treg cells through TGF $\beta$ release, reinforcing the induction of the immunosuppressive functions of the TME (126-128). Induction of adenosine receptor A2b is triggered by the hypoxia-induced factor (HIF)-regulated elements during tumor hypoxia and is involved in skewing DCs to TH2 triggering phenotype, sustaining M2-like macrophage induction, and reinforcing tumor angiogenesis (129). Although regDCs and MDSCs have cell-type specific functional properties, their capability of regulating tumor angiogenesis in the TME appears similar to the one of M2-like TAMs and N2 neutrophils, leading to production of several soluble factors such as VEGF, FGF2, BV8, and MMP9 (130).

\section{MAST CELLS}

Mast cells (MCs) are bone marrow-derived multifunctional immune cells first identified in human tumors by Paul Ehrlich in the 1870s $(69,131)$. MCs and their mediators exert a host protective immune response against noxious agents, viral and microbial pathogens (132-135), but are also associated with a detrimental role in allergic diseases (69). Increased number of MCs have been observed in tumor and peritumor tissues of cancer patients (136); their role in cancer insurgence and progression is tumor dependent $(69,131)$. Contrasting roles of MCs in supporting or inhibiting tumor progression have been reported (131). In solid neoplasms including thyroid, gastric, pancreatic, bladder cancers, prostate adenocarcinomas, and hematological malignancies, MCs have been associated with protumorigenic activity $(69,131,137)$. In breast cancer (131) and in murine model of prostatic neuroendocrine tumors (137), MCs have antitumor activities. These data clearly suggest that the role of MCs in cancer is tumor-type dependent and is tuned by the local microenvironment (Figures 1 and 2). Antitumor activities by MCs are related to their ability to induce target cell cytotoxicity by releasing $\mathrm{TNF} \alpha$ or by induction of ROS. Protumorigenic activities of MCs include contribution to the induction of an acidic and immunosuppressive TME, through adenosine production in the extracellular milieu. Prometastatic functions of MCs are mediated by the release of TGF $\beta$, which induce tumor cells to undergo epithelial to mesenchymal transition. MC releases proangiogenic factors including FGF2, VEGFA, TNFs, CXCL8 $(69,131)$, diverse proteases, such MMPs (MMP9 mostly), as well as chymase and tryptase that modify pro-MMPs to their active forms $(5,138)$. MC deficient tumor-bearing mice show a reduced angiogenesis and metastatic capacity $(138,139)$. In renal cell carcinoma, infiltrating MCs have been found to support angiogenesis by modulating PI3K/AKT/GSK3 $\beta / \mathrm{AM}$ signaling (140). Following activation of c-KitR/SCF, MCs can release tryptase that, acting on PAR2 in tumor cells, induce endothelial and tumor cell proliferation in a paracrine manner, leading to tumor cell invasion and metastasis (141). Tryptase released by MCs sustain angiogenesis in pancreatic cancers by activating the angiopoietin-1 pathway. Tryptase producing MCs correlate with angiogenesis in locally advanced colorectal cancer patients (142). 
Immunohistochemical analysis showed that tryptase-positive MCs in multiple myeloma were associated with higher levels of MMP9, ANG2, and angiogenin (143) and could contribute to vasculogenic mimicry (144). Tryptase appears the key mediator for protumor activity of MCs, since it is involved in cell growth, tumor-induced angiogenesis, and invasion $(145,146)$, thus it appears to be a promising target for MC-related angiogenesis. Tryptase inhibitors originally designed as anti-allergic drugs could exert promising antitumor and antiangiogenic activity and could be proposed as repurposed drugs also in combination with immune therapy.

\section{$\gamma \delta \mathrm{T} 17$ CELLS}

Gammadelta T cells are lymphoid cells characterized by unique features resembling innate cells in their capacity to recognize conserved non-peptide antigens expressed by stressed cells. They also resemble adaptive cells because of their ability to undergo clonal expansion and to develop antigen-specific memory (147). These cells are involved in the early phase of immune responses and produce pro-inflammatory factors such as IFN $\gamma$ and TNF $\alpha$ and IL-17, activating other effector immune cells against virus, bacteria, and tumor cells but also stimulating inflammation and exacerbation of autoimmune diseases. They comprise different functional subsets.

Although there are some conflicting data on the role of $\gamma \delta \mathrm{T}$ cells inside the TME, it is believed that the subset $\gamma \delta \mathrm{T} 17$ cells, specialized in the IL-17 release, can actively participate in the angiogenic process $(147,148)$ (Figures 1 and 2). It has been shown that $\gamma \delta \mathrm{T} 17$ cells release IL-17, CXCL8, CFS2 (also known as GM-CSF), and TNF $\alpha$, and are able to support survival of MDSCs (149). Tumor cells over-expressing IL-17 showed significant tumor growth and new vessel formation (150). Since IL-17 has no direct effect on the proliferation of ECs, the proangiogenic effect is likely to be exerted through the enhancement of VEGF and/or CXCL8 by tumor cells (151). On the contrary, mice lacking IL-17 showed limited tumor growth and the vascular density in tumor tissues was decreased (152). There is evidence that IL-17 responsiveness can be an independent prognostic factor for overall survival in colorectal patients (153), high expression of IL-17 was shown to be associated with high microvessel density and was associated with VEGF production from tumor cells. More recently, it has been shown that IL-17 activates STAT3 in non-small cell lung carcinomas (NSCLC) cells and that treatment of HUVECs with IL-17 in vitro promoted the formation of vessel-like tubes in a dose-dependent manner (154). The GIV protein $(\mathrm{G} \alpha$-interacting vesicle-associated protein, also known as Girdin) modulates the crucial signaling pathways in processes including macrophage chemotaxis, wound healing, and cancer metastasis and can be a target of STAT3 activation in NSCLC cell lines. IL-17-dependent STAT3/GIV signaling pathway is responsible for VEGF release from cancer cells and promotion of tumor angiogenesis, and GIV expression positively correlates with $\mathrm{IL}-17^{+}$cell presence and increased microvessel densities and predicts poor survival of NSCLC patients (154).

IL-17 in the TME in the CMS-G4 fibrosarcoma tumor model was largely derived from tumor-infiltrating $\gamma \delta \mathrm{T}$ cells, and anti-cytokine mAb treatment revealed that the $\gamma \delta \mathrm{T}$ cells require the presence of IL-6, IL-23, and TGF $\beta$ signaling (152). In gallbladder cancer (GBC) patients, $\gamma \delta \mathrm{T} 17$ cells are increased in peripheral blood and in the population of tumor-infiltrating lymphocytes (155). GBC patients with high $\gamma \delta T 17, \mathrm{TH} 17$, and Treg cells showed poor overall survival (155). A GBC (OCUG-1) cell line that is responsive to IL-17, treated with cell-free supernatant from $\gamma \delta T 17$ cells, upregulates VEGF production, and this effect is IL-17 dependent (155). The proangiogenic action of $\gamma \delta \mathrm{T} 17$ cells on GBC was confirmed by protein angiogenesis array performed on cell-free supernatants derived from these cells. The assay showed IL-17-dependent upregulation of several important angiogenesis factors in OCUG-1 cells, such as VEGF, angiogenin, uPA, MMP9, CCL2, CXCL16, CSF2, and coagulation factor III, but also stimulation of production of antiangiogenic factors, including thrombospondin-1, TIMP1, serpine-1, and platelet factor 4. A recent report has shown that IL-17-secreting $\gamma \delta \mathrm{T}$ cells are dependent on CCR6 for homing to inflamed skin (156). Drugs targeting CCR6 or factors involved in $\gamma \delta T 17$ cell proangiogenic polarization should be studied for potential use in addition with immunotherapy.

\section{INNATE LYMPHOID CELLS}

Innate lymphoid cells represent a recently identified heterogeneous family of mononuclear hematopoietic cells, found mostly in solid tissues (157-160). Based on their lymphoid morphology, surface antigens, transcription factor expression, and cytokine productions (TH1, TH2, and TH17-like), ILCs have been classified into three major groups, termed as ILC1, ILC2, and ILC3 (161). ILC1s are characterized by IFN $\gamma$ release and are Tbet dependent; ILC2 produce type 2-cytokines, such as IL-5 and IL-13, and require GATA3 expression; ILC3s produce IL-17 and/ or IL-22 and are dependent on ROR $\gamma \mathrm{t}$ (162). ILCs are endowed with potent pleiotropic effects in early responses against infections and are involved in several pathologies including cancer. Aberrant activation, proliferation, and functions of ILCs support severe inflammation and damages in diverse organs, including the gut, lung, liver, and skin (163-168). Whether ILCs can be defined as friends or foes in cancer insurgence and progression is still a matter of debate $(157,158,160)$. ILCs are characterized by high-cell plasticity and can be easily interconverted into their different subsets upon TME stimuli [especially ILC1-ILC3 interconversion (169)].

IFN $\gamma^{+}$ILC1s have been associated with both antitumor and protumor effects (Figure 1), the latter induced by triggering of MDSCs and inducing indoleamine 2,3-dioxygenase activity (157). A protective role exerted by a novel type of ILC1-like cells has been shown in a murine model of mammary carcinogenesis (170). NK cells, that will be discussed, later have also been included in the ILC1 subclass.

ILC2s can release type 2 cytokines, such as IL-5 and IL-13, and CSF2 in response to IL-25 and IL-33. IL-13/IL-13R interaction in breast cancer and cholangiocarcinoma cells in association with recruitment and induction of TGF $\beta$-producing MDSCs and Treg has been reported to induce tumor cell growth and migration (171), and tumor immune escape (172). Release 
of IL-13 by ILC2s promotes M2-like TAM polarization and amplification (172).

Among the ILC subgroups, ILC3s are the more investigated for their contribution to carcinogenesis. They comprise several subsets: lymphoid tissue inducer (LTi) cells, first discovered for their function in the formation of lymphoid tissue during organogenesis, NCR (NKp46, NKp44)+ ILC3 and NCR ${ }^{-}$ILC3. Overall, the pro-tumor activities of ILC3s are mainly linked to the induction of chronic inflammation by secretion of IL-17 and IL-22, in particular in the gut, through their response to IL-23 (173).

ILC3s preserve epithelial integrity and maintain tissue homeostasis by secretion of IL-22. Production of IL-17 by ILC3s can have a role in promoting tumorigenesis, tumor growth, and angiogenesis (174-176). Growing evidence from mouse tumor models marks ILC3s as cells involved in the recruitment of MDSCs, Treg cells, and in the promotion of M2-like macrophages in the TME. At the moment, the real contribution in human cancers remains to be fully elucidated $(177,178)$. ILC3s have also been shown to play a role in carcinogenesis in models of bacteria-induced colorectal cancer, through the release of IL-22 (179). The involvement of LTi-like ILC3s has been shown in the induction of tumor migration via lymphatics in patients with triple-negative breast cancers (180). In the 4T1.2 syngeneic mouse breast model, ILC3s are recruited in the primary tumor through CCL21, and then they trigger tumor stromal cells to release CXCL13, which leads to the induction of lymphotoxin and receptor activator of nuclear factor $\kappa$-B ligand, that in turn promotes lymphangiogenesis and stimulate tumor cell motility (180). A correlation exists between invasive aggressive behavior in breast cancer patients and gene expressed by ILC3s such as CXCL13, CCL19, CCL21, and CXCR5 and CCR7 (181). ILC3s have been shown to promote the formation of tertiary lymphoid structures (TLS), involved in tumor progression and lymph nodal metastasis (182). The protumor or antitumor roles of TLS are still debated $(183,184)$. NKp46 ${ }^{+} \mathrm{NKp} 44^{+}$LTi-like ILC3s are present in the TME near intra-tumor TLS and may interact directly with tumor cells by sensing and recognizing transformed cells through the NKp44 receptor. Tumorinfiltrating NKp46 $6^{+} \mathrm{NKp} 44^{+}$LTi-like ILC3s are endowed with ability to release several types of pro-inflammatory cytokines and chemokines, and their increased numbers correlated with intra-tumor TLS and predict favorable clinical outcome (185). Accumulation of neuropilin (NRP) $1^{+}$LTi-like ILC3s has been found in inflamed tissues of patients with chronic obstructive pulmonary disease and in smokers, in association with VEGF production (186). Immunohistochemistry analysis of inflamed tissues revealed that the majority of $\mathrm{ROR} \gamma \tau^{+} \mathrm{NRP} 1^{+}$cells were co-localized with blood vessels and in the alveolar parenchyma, suggesting their contribution to angiogenesis and induction of lung TLS. Apart from IL-22 and IL17, the pro-inflammatory LTi-like NRP1+ ILC3 subset was also found to release CSF2, TNF $\alpha$, B-cell-activating factor, and CXCL8, possibly contributing to angiogenesis.

Due to the recent discovery of the non-NK ILCs and the incomplete knowledge of the role in tumor and angiogenesis, targeting strategies have not been yet developed.

\section{NK CELLS}

Natural killer cells are bone marrow-derived large granular effector lymphocytes of the innate immune system that can potentially control tumor growth by their cytotoxic activity (187), which are now classified as a subset of ILC1 (161). Based on surface density expression of CD56, an isoform of the human neural cell adhesion molecule, and of CD16, the low-affinity Fcy receptor, two main subpopulations of peripheral blood NK cells have been identified in humans: the $\mathrm{CD} 56^{\text {dim }} \mathrm{CD} 16^{+}$and the $\mathrm{CD} 56^{\text {bright }} \mathrm{CD} 16^{- \text {llow }}$ NK cell subset, representing about $90-95 \%$ of peripheral blood NK cells and about $5-10 \%$ of peripheral blood NK cells, respectively. $\mathrm{CD} 56^{\mathrm{dim}} \mathrm{CD} 16^{+} \mathrm{NKs}$ can release high quantity of perforin and granzymes and are cytotoxic when encountering cells with high-activating ligands and low inhibitory (mostly class I MHC) ligands or when mediating antibody-dependent cell cytotoxicity (187). Although weak long-term cytokine producers, these cells have the ability to quickly $(2-4 \mathrm{~h})$ secrete high amounts of cytokines $(188,189)$. CD $56^{\text {bright }} \mathrm{CD} 16^{- \text {llow }} \mathrm{NKs}$, are poorly cytotoxic, but can release several cytokines, including IFN $\gamma$, TNF $\alpha$, and GM-CSF. However, there is an increasing awareness of the complexity of NK cell subsets and the role of the TME (190-193). Mature NK cells express the PD-1 receptor, and engagement with the programmed death-ligand 1 (PD-L1) ligand results in impaired antitumor NK cell activity $(194,195)$. Disruption of this PD-1/ PD-L1 by blocking antibodies partially restores their antitumor activity $(194,195)$. Another recently identified NK checkpoint is the IL-1R8 (also known as SIGIRR, or TIR8), which is expressed on human and murine NK cells (196). Mice lacking IL-1R8 are protected against chemically-induced tumors and metastatic dissemination (196). Mice lacking the cytokine-induced SH2containing protein CIS also had protection toward chemically induced tumors and metastatic disease (197).

A third NK cell subset has been identified in the decidua during pregnancy, termed decidual or uterine NK cells (dNK). dNK cells acquire the $\mathrm{CD} 56^{\text {superbright }} \mathrm{CD} 16^{-} \mathrm{KIR}^{+}$phenotype (198), are poorly cytotoxic, and secrete proangiogenic cytokines, including VEGF, placental growth factor (PlGF), CXCL8, and IL-10 (198-200) and are critical for decidual vascularization and spiral artery formation $(199,201)$. Early on in pregnancy, dNK increase up to $70 \%$ of the local lymphocytes and $30-40 \%$ of all decidual cells (202). While it has been exhaustively demonstrated that NK cells have important proangiogenic roles in the uterine vasculature, their contribution to tumor angiogenesis still represent a poorly explored topic (Figure 1). The TME has been extensively reported to be crucial in shaping NK cell functions (203). We were the first to report a proangiogenic NK cell polarization in peripheral blood (TANKs) and tumor-infiltrating NK cells (TINKs) (204) in NSCLC patients. We showed that the $\mathrm{CD} 56^{\text {bright }} \mathrm{CD} 16^{-} \mathrm{NK}$ cells, the predominant subset infiltrating NSCLC tissues and a minor subset in adjacent lung and peripheral blood, are associated with VEGF, PlGF, and IL-8 production (Figure 2). Functional assays indicated that supernatants derived from NSCLC CD56 ${ }^{\text {bright }} \mathrm{CD} 16^{-}$NK cells induce EC chemotaxis and formation of capillary-like structures in vitro, and that these effects were even stronger in TANKs isolated from subset of squamous carcinoma patients than in adenocarcinoma. 
TGF $\beta$ is associated with $\mathrm{dNK}$ polarization $(205,206)$ and is present in the TME. A combination of TGF $\beta$, hypoxia, and a demethylating agent induces a dNK-like phenotype in healthy donor NK cells (207). A recent report indicated that TGF $\beta$ converted NK cells into other ILC1 subpopulations that were unable to control local tumor growth and metastasis (208). We observed that TGF $\beta 1$ upregulates VEGF and PIGF in healthy donor NK cells (204).

Tumor-infiltrating NK cells operate within a hypoxic TME. Hypoxia has been extensively reported to modulate immune cell response as well as driving angiogenesis (209). Murine NK cells genetically depleted of HIF $1 \alpha$ continued to have impaired cell cytotoxicity, yet tumors grew more slowly in these mice (210). Tumors in these mice had numerous immature vessels with hemorrhages that resulted in severe hypoxia, which favored metastasis. Genetic inactivation of STAT5, which is necessary for NK cell-mediated cancer immunosurveillance, increases VEGFA in NK cells and stimulates angiogenesis in mouse lymphoma models and on healthy donor-derived NK cells (211). The aminobiphosphonate zoledronic acid, largely employed as an immunomodulatory agent and able to decrease VEGF levels, has been surprisingly found to synergize with IL-2 in inducing proangiogenic features in TINKs, acting on VEGF/VEGFR1 axis (212). Thus, therapeutic intervention could act as a double edge sword in NK cell response to tumors.

\section{PHARMACOLOGICAL AND IMMUNOTHERAPEUTIC COMBINATION TARGETING THE TME}

Extensive studies on TME led to a shift from a tumor-centered view of cancer onset to the role of a more complex tumor ecosystem in which cellular and molecular components are as influential as cancer cells themselves for cancer development and metastatic behavior. This knowledge led to the rapid development of therapeutic approaches aimed at restoring altered/ aberrant host immune cell response, by accelerating/pushing efficient tumor eradication, stimulating immune cells of the host (213). The use of immune checkpoint blockers (ICBs) induces reactivation of key immune cell players and has been demonstrated to have great clinical benefits in several tumors (214). Available ICBs target cytotoxic T lymphocyte-associated protein 4 (CTLA-4), programmed cell death 1 (PD-1) receptor, and its ligand PD-L1. Known ICBs are: Ipilimumab, a mAb-blocking CTLA4, approved in patients with unresectable or metastatic melanoma. Pembrolizumab, a mAb-blocking PD-1, initially licensed for use in patients with unresectable or metastatic melanoma experiencing disease progression on ipilimumab. Pembrolizumab has been recently made available for other types of cancer (metastatic Non-Small Cell Lung Cancer, Head and Neck Cancer, Hodgkin's Lymphoma, Urothelial Carcinoma and Gastric Cancer). Nivolumab is another mAb directed to PD-1 approved

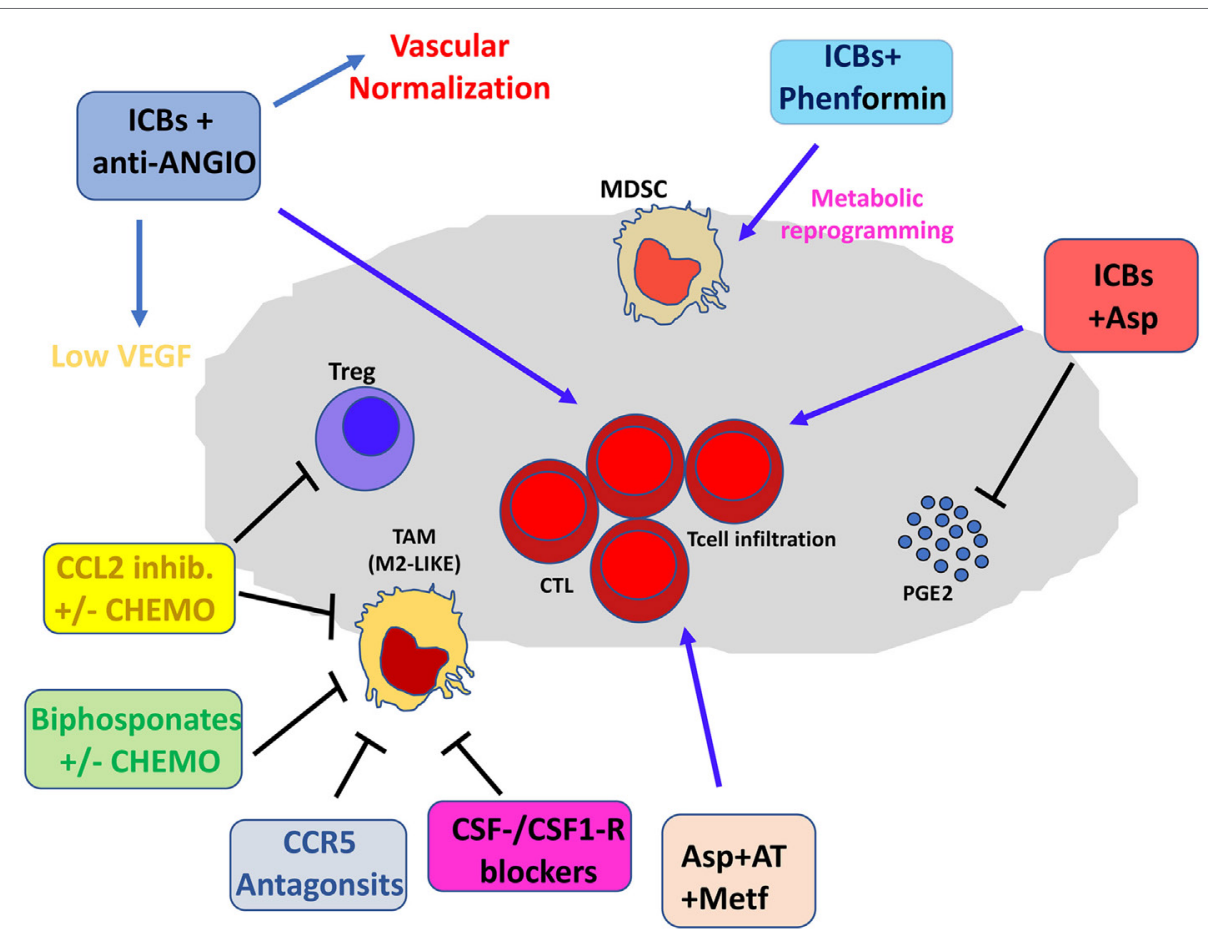

FIGURE 3 | Pharmacological and immunotherapeutic combination targeting the tumor microenvironment (TME). Immune checkpoint blockers (ICBs) can be employed in diverse pharmacological combinations resulting in clinical benefit for patients. ICBs + antiangiogenic agents result both in inhibition of aberrant angiogenesis and vascular normalization with subsequent efficient T cell infiltration. CCL2 inhibitors combined with chemotherapy dampen induction of M2-like tumor-associated macrophages (TAMs) in the TME and T regulatory (Treg) proliferation. Bisphosphonates + chemotherapy target M2-like TAMs. Anti-Angio, VEGF inhibition and eventually angiopoietin-2 blockade; Asp, aspirin; AT, atenolol; Metf, metformin; Chemo, standard chemotherapeutic drugs. 
for use in individuals with unresectable or metastatic melanoma non-responding to other treatments, as well as in patients with metastatic NSCLC, or after platinum-based chemotherapy. Atezolizumab is a PD-L1-blocking antibody for the treatment of locally advanced or metastatic urothelial carcinoma. Despite the strong clinical success of cancer immunotherapy with checkpoint inhibitors and other immune modulating agents, most patients still do not experience a durable response (215) and many do not respond at all. To overcome this issue, several strategies combining immune to targeted therapy have been developed.

The gut microbiome, which has a significant influence on the local and systemic immune system, can influence the outcome of ICB therapy in preclinical mouse models and humans (216-219). A recent study on the gut and oral microbiome of a cohort of melanoma patients undergoing an anti-PD-1 therapy revealed crucial differences in the diversity and composition of the patients' gut microbiome of responders vs. non-responders (216). Analysis of patient fecal microbiome in responding melanoma patients indicated significantly higher relative abundance of bacteria of the Ruminococcaceae family that also correlated with presence of $\mathrm{CD}^{+} \mathrm{T}$ cells in the TME. Fecal microbiota transplantation in germ-free recipients showed that mice which had been transplanted with stool from responders to anti-PD-1 therapy had significantly reduced tumor size and higher density of $\mathrm{CD}^{+} \mathrm{T}$ cells in comparison to mice receiving stool from non-responders to PD-1 blockade (216). Another recent study on different epithelial tumors in mice and patients indicated correlations between clinical responses to ICBs and the relative abundance of Akkermansia muciniphila (217). Hence, the gut microbiome can strongly influence the outcome of cancer patients receiving PD-1 blockade therapy. However, the mechanisms related to these immunomodulatory effects of $A$. muciniphila remain elusive. It is conceivable that an integral intestinal barrier is associated with a minor systemic inflammation, and specific bacterial families such as Ruminococcaceae and/or A. muciniphila may induce beneficial bacterial metabolites that prevent leaky colon and systemic immunosuppression, paving the way to the possibility to manipulate the gut ecosystem to implement ICB therapy (218).

All recent preclinical and clinical data suggest that the localization, quality, and quantity of non-cancerous cells, including lymphoid and myeloid cells, within the TME play a major role in shaping response to immune checkpoint blockade (Figures 3 and 4). Other TME cells, such as fibroblast and ECs, could

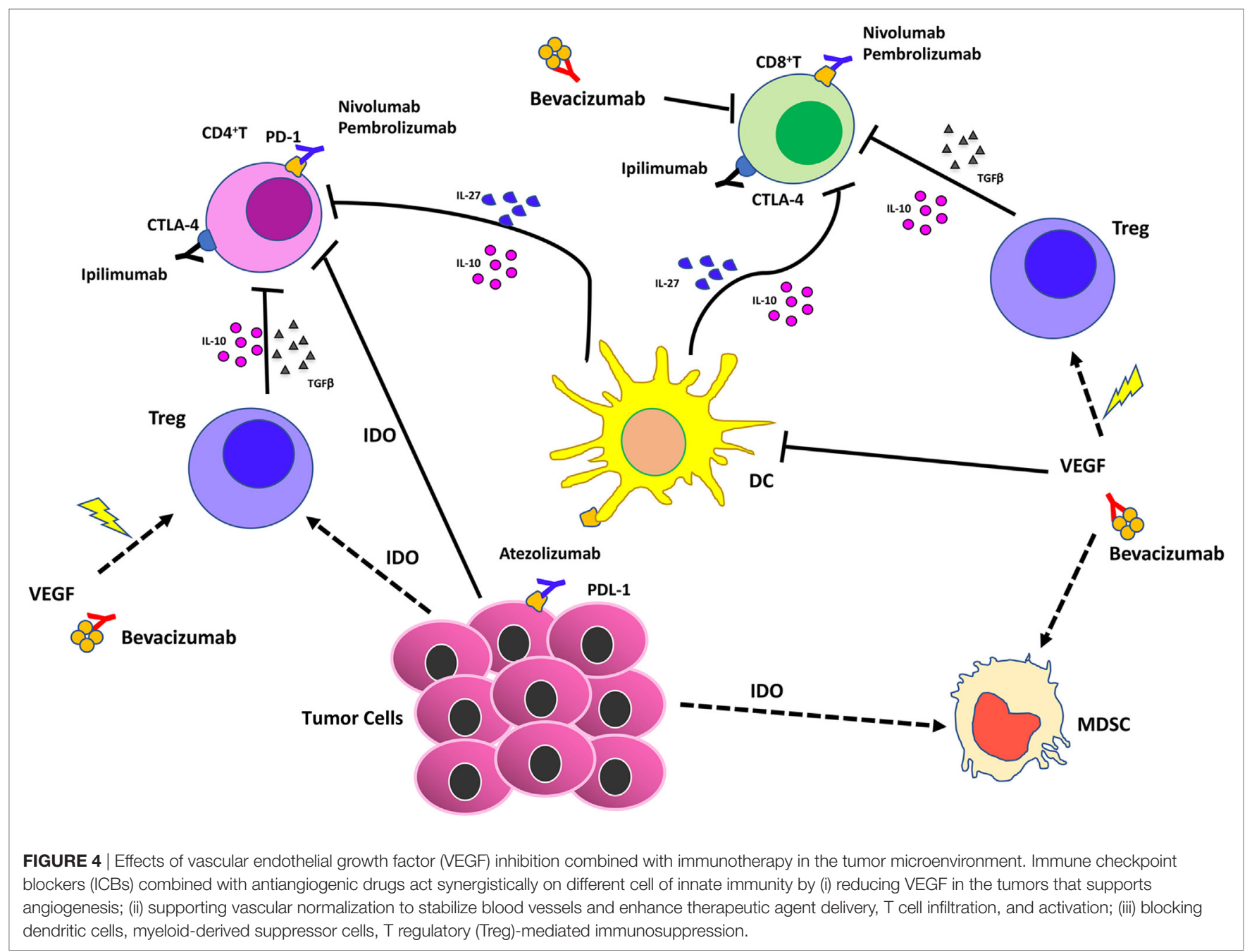


contribute to shaping the immune contest. An emerging role is demonstrated for the angiogenic factor VEGF.

Vascular endothelial growth factor blocks $\mathrm{T}$ cell infiltration into the tumor by inhibition of adhesion molecules on ECs (220). VEGF has also been reported to inhibit antigen presentation by DCs, to enhance the Treg expansion, and to mediate PD-1 upregulation on tumor-infiltrated $\mathrm{T}$ cells $(221,222)$. Antiangiogenic treatments such as anti-VEGF antibody bevacizumab and the diverse multi-tyrosine kinase receptor inhibitors targeting the VEGFR family have been largely employed in the clinic, combined with chemotherapy, in particular in colorectal and renal cancer. They have shown significant but moderate benefits in patients' overall survival (223). Excessive pruning of vessels following antiVEGF treatment has been reported to associate with increased hypoxia that, through upregulation of CXCL12/CXCR4 axis and HIF1 $\alpha$, supports M2-like TAM, MDSC, and Treg recruitment, thus supporting tumor progression (223). Tumors show considerable variation in their responses to antiangiogenic therapy, however, given the immunosuppressive action of VEGF $(47,222,224)$, VEGF inhibitors could combine with the ICBs to enhance therapeutic effects.

Therefore, combination with antiangiogenic agents, and/or anti-inflammatory drugs has a strong rationale $(47,225,226)$ but it is still in its infancy. Preclinical and clinical studies in renal cancer showed that the combination of anti-CTLA- 4 with sunitinib (227) resulted in decreased Treg and increased CD8 ${ }^{+} \mathrm{T}$ cell infiltration (Figure 4). Conversely, increased PD-L1 expression has been observed following treatments with sorafenib, sunitinib, or bevacizumab in a HIF1 $\alpha$-dependent and -independent manner (228). Growing evidence supports the notion that the targeting of VEGF signaling could result in the induction of tumor vasculature normalization, enhancement of immune cells extravasation, and synergy with immunotherapy (229-231). The combination of bevacizumab and ipilimumab has been reported to be associated with clinical benefits in patients with melanoma (232), and has been found to target Galectin-1 (233-235). Blocking of VEGFA and angiopoietin-2 using a bispecific antibody in murine models resulted in activation of cytotoxic T lymphocytes, which upregulated PD-L1, and inhibition of PD-1 axis further improved the efficacy of this therapy (236). Another rationale for the combination of ICBs and antiangiogenic agents is that antiangiogenic agents "normalize" the tumor vasculature, inducing intra-tumor high endothelial venules, thus favoring enhanced T-cell infiltration, antitumor CTL activity, and tumor cell destruction (236, 237). ICBs in combination with antiangiogenic agents may act as a promising strategy also to dampen the proangiogenic features of immune-infiltrating cells, such as TAMs, MDSCs, and NK cells, acting as re-polarizing agents $(226,238,239)$.

Chronic inflammation, another relevant hallmark of cancer (3), directly stimulates angiogenesis to support tumor progression $(5,7)$ and immune suppression $(16,17,107,225,226)$. The immunosuppressive inflammatory TME is a key obstacle to cancer immunotherapy (Figures 3 and 4). Thus, targeting chronic inflammation could be one strategy to combat the immunosuppressive TME and enhance the activities of ICBs. One example is targeting the PI $3 \mathrm{~K} \gamma$, which has a strong effect on myeloid cells, preventing immune suppression and enhancing the effects of
ICBs in vivo (240, 241) (Figures 3 and 4). Another example of therapy that could synergize with ICBs is targeting the CXCR2 axis, which recruits neutrophils into the premetastatic niche (98).

The combination of anti-inflammatory agents with ICBs can be exploited to support immunotherapy. Regular use of aspirin, the most commonly employed nonsteroidal anti-inflammatory drug, has been widely reported to reduce incidence and mortality of colorectal cancer (242) and many other adenocarcinomas (243). A recent U.S. population-based study reported a stronger survival association of post-diagnosis aspirin use in CRC patients with lower-level PD-L1 expression when compared with those with higher-level of PD-L1 expression (244). Experimental data supported a synergistic effect between aspirin and anti-PD1 antibody in mutant Braf(V600E) melanoma cells (245). The synergistic effects resulted also in increased $\mathrm{T}$ cell-mediated immune responses and decreased PGE2 production (245). In experimental models, we showed that aspirin or the beta-blocker agent atenolol can augment the activity of metformin, a biguanide largely employed in type 2 diabetes management and that have been associated to reduced risk of developing diverse cancers,
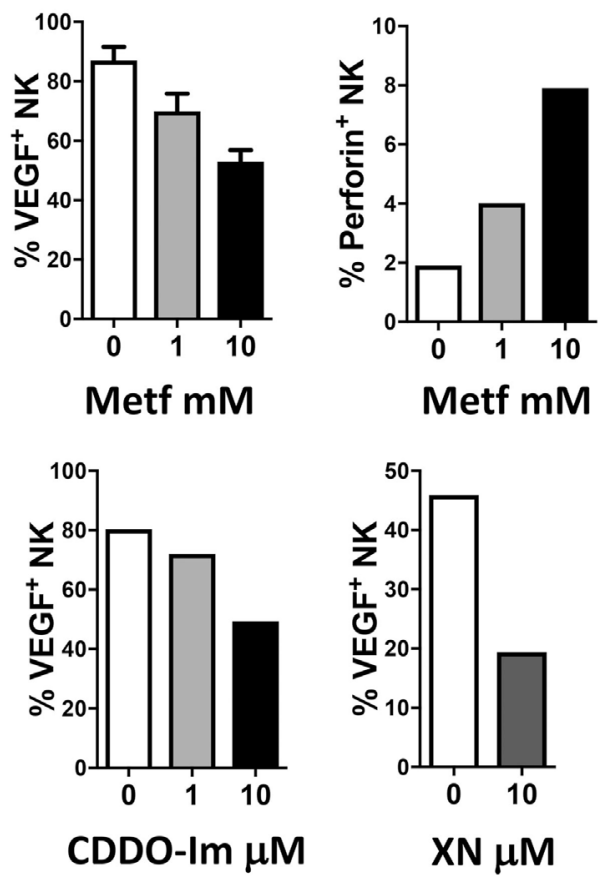

FIGURE 5 | Examples of effects of repurposed drugs and phytochemicals on natural killer (NK) cell repolarization. The biguanide metformin (Metf), the synthetic triterpenoid 1[2-Cyano-3,12-dioxooleana-1,9(11)-dien-28-oyl] imidazole (CDDO-Im) and the hop flavonoid xanthohumol (XN) can decrease vascular endothelial growth factor (VEGF) production in non-small cell lung cancer associated NK cells and at the same time can upregulate perforin production. Graphs show data obtained from multicolor flow cytometry analysis of total NK cells (CD45+CD14-CD3-CD56+ cells) from peripheral blood samples of patients with non-small cell lung carcinomas (as in 204, protocol number 0024138/2013), exposed for $24 \mathrm{~h}$ to the compounds at indicated concentrations. These examples sustain the action of antiinflammatory chemopreventive drugs in innate immune cells repolarization supporting the rationale for future combinations with immunotherapy. 
including breast cancers (Figure 4), targeting both neoplastic cells and the TME $(246,247)$. Metformin and phenformin affect the angiogenesis pathway (248-250) and modulate the immune response and the microbiome $(251,252)$. Phenformin enhances PD-1 immunotherapy (115). CDDO-Im (a synthetic triterpenoid: 1[2-Cyano-3,12-dioxooleana-1,9(11)-dien-28-oyl]imidazole) has an extensive documentation as an immunomodulation agent (253-255), and xanthohumol (XN) (a prenylated chalcone flavonoid) is an antileukemia agent (256-259) and is a polarizing agent in murine models of breast cancer (260). Phytocompounds and their synthetic derivatives are able to polarize macrophages inducing anti-tumorigenic phenotype/functions (253, 260-262). For example, we show that NSCLC patient TANKs treated with metformin, CDDO-Im, and XN decreases VEGF production (Figure 5) and increases perforin content. Thus, we would like to indicate the use of non-toxic or low-toxic re-polarization agents endowed with anti-inflammatory chemopreventive properties to be combined with ICBs.

\section{CONCLUSION}

The immune checkpoint inhibitors have posed a distinct milestone in cancer therapy. However, several patients do not respond to the ICBs, or have a relapse, with eventual long-term toxicity (i.e., autoimmune diseases). The polarized TME is crucial in the outcome of the patient response to an ICB, thus treating an inflamed or vascularized TME, could theoretically enhance

\section{REFERENCES}

1. Joyce JA, Pollard JW. Microenvironmental regulation of metastasis. Nat Rev Cancer (2009) 9(4):239-52. doi:10.1038/nrc2618

2. Virchow RLK. Die CELLULARPATHOLOGIE in ihrer Begründung auf physiologische und pathologische Gewebelehre. [Cellular Pathology As Based Upon Physiological and Pathological Histology]. Berlin: August Hirschwald (1858). Published in English in 1863 by J. B. Lippincott, Philadelphia.

3. Hanahan D, Weinberg RA. Hallmarks of cancer: the next generation. Cell (2011) 144(5):646-74. doi:10.1016/j.cell.2011.02.013

4. Bruno A, Pagani A, Magnani E, Rossi T, Noonan DM, Cantelmo AR, et al. Inflammatory angiogenesis and the tumor microenvironment as targets for cancer therapy and prevention. Cancer Treat Res (2014) 159:401-26. doi:10.1007/978-3-642-38007-5_23

5. Bruno A, Pagani A, Pulze L, Albini A, Dallaglio K, Noonan DM, et al. Orchestration of angiogenesis by immune cells. Front Oncol (2014) 4:131. doi:10.3389/fonc.2014.00131

6. De Palma M, Biziato D, Petrova TV. Microenvironmental regulation of tumour angiogenesis. Nat Rev Cancer (2017) 17(8):457-74. doi:10.1038/nrc. 2017.51

7. Noonan DM, De Lerma Barbaro A, Vannini N, Mortara L, Albini A. Inflammation, inflammatory cells and angiogenesis: decisions and indecisions. Cancer Metastasis Rev (2008) 27(1):31-40. doi:10.1007/s10555-0079108-5

8. Shaked Y, McAllister S, Fainaru O, Almog N. Tumor dormancy and the angiogenic switch: possible implications of bone marrow-derived cells. Curr Pharm Des (2014) 20(30):4920-33. doi:10.2174/1381612819666131125153536

9. Stockmann C, Schadendorf D, Klose R, Helfrich I. The impact of the immune system on tumor: angiogenesis and vascular remodeling. Front Oncol (2014) 4:69. doi:10.3389/fonc.2014.00069

10. Glass CK, Natoli G. Molecular control of activation and priming in macrophages. Nat Immunol (2016) 17(1):26-33. doi:10.1038/ni.3306 the efficacy of these drugs. We suggest to combine ICBs with drugs that inhibit VEGF (232) or to employ drugs that eliminate the protumor inflammatory cells (for example, trabectedin to eliminate TAMs) or to treat with anti-inflammatory agents that will "re-polarize" the immune cells, for example, the repurposed drugs (metformin) and phytochemicals and their synthetic derivatives (CDDO-Im and XN) or both. Since phytochemicals and their synthetic derivatives often protect the cardiovascular system from chemotherapy induced damage $(248,263,264)$, we propose, as a first-line therapy for difficult and metastatic tumors, to pretreat with phytochemicals or synthetic derivatives, then continue treatment and add sequentially a VEGF blocker, ICBs, and chemotherapy (to trigger the immunogenic cell death). This will set the stage for the ICBs to become highly effective in additional patients.

\section{AUTHOR CONTRIBUTIONS}

All authors listed have made a substantial, direct, and intellectual contribution to the work and approved it for publication.

\section{FUNDING}

This work was supported by University of Insubria Fondi di Ateneo per la Ricerca "FAR 2016" and "FAR 2017" and the AIRC (Associazione Italiana per la Ricerca sul Cancro).

11. Sica A, Erreni M, Allavena P, Porta C. Macrophage polarization in pathology. Cell Mol Life Sci (2015) 72(21):4111-26. doi:10.1007/s00018-015-1995-y

12. Murray PJ, Allen JE, Biswas SK, Fisher EA, Gilroy DW, Goerdt S, et al. Macrophage activation and polarization: nomenclature and experimental guidelines. Immunity (2014) 41(1):14-20. doi:10.1016/j.immuni.2014.06.008

13. Mantovani A. Reflections on immunological nomenclature: in praise of imperfection. Nat Immunol (2016) 17(3):215-6. doi:10.1038/ni.3354

14. Mantovani A, Marchesi F, Malesci A, Laghi L, Allavena P. Tumour-associated macrophages as treatment targets in oncology. Nat Rev Clin Oncol (2017) 14(7):399-416. doi:10.1038/nrclinonc.2016.217

15. Sica A, Bronte V. Altered macrophage differentiation and immune dysfunction in tumor development. J Clin Invest (2007) 117(5):1155-66. doi:10.1172/ JCI31422

16. Coussens LM, Zitvogel L, Palucka AK. Neutralizing tumor-promoting chronic inflammation: a magic bullet? Science (2013) 339(6117):286-91. doi:10.1126/science.1232227

17. Mantovani A, Allavena P, Sica A, Balkwill F. Cancer-related inflammation. Nature (2008) 454(7203):436-44. doi:10.1038/nature07205

18. Lan C, Huang X, Lin S, Huang H, Cai Q, Wan T, et al. Expression of M2-polarized macrophages is associated with poor prognosis for advanced epithelial ovarian cancer. Technol Cancer Res Treat (2013) 12(3):259-67. doi: $10.7785 /$ tcrt.2012.500312

19. Qian BZ, Pollard JW. Macrophage diversity enhances tumor progression and metastasis. Cell (2010) 141(1):39-51. doi:10.1016/j.cell.2010.03.014

20. Ryder M, Ghossein RA, Ricarte-Filho JC, Knauf JA, Fagin JA. Increased density of tumor-associated macrophages is associated with decreased survival in advanced thyroid cancer. Endocr Relat Cancer (2008) 15(4):1069-74. doi:10.1677/ERC-08-0036

21. Steidl C, Lee T, Shah SP, Farinha P, Han G, Nayar T, et al. Tumor-associated macrophages and survival in classic Hodgkin's lymphoma. N Engl J Med (2010) 362(10):875-85. doi:10.1056/NEJMoa0905680

22. Xu J, Escamilla J, Mok S, David J, Priceman S, West B, et al. CSF1R signaling blockade stanches tumor-infiltrating myeloid cells and improves the 
efficacy of radiotherapy in prostate cancer. Cancer Res (2013) 73(9):2782-94. doi:10.1158/0008-5472.CAN-12-3981

23. Forssell J, Oberg A, Henriksson ML, Stenling R, Jung A, Palmqvist R. High macrophage infiltration along the tumor front correlates with improved survival in colon cancer. Clin Cancer Res (2007) 13(5):1472-9. doi:10.1158/10780432.CCR-06-2073

24. Shimura S, Yang G, Ebara S, Wheeler TM, Frolov A, Thompson TC. Reduced infiltration of tumor-associated macrophages in human prostate cancer: association with cancer progression. Cancer Res (2000) 60(20):5857-61.

25. Welsh TJ, Green RH, Richardson D, Waller DA, O'Byrne KJ, Bradding P. Macrophage and mast-cell invasion of tumor cell islets confers a marked survival advantage in non-small-cell lung cancer. JClin Oncol (2005) 23(35):8959-67. doi:10.1200/JCO.2005.01.4910

26. Biswas SK, Mantovani A. Macrophage plasticity and interaction with lymphocyte subsets: cancer as a paradigm. Nat Immunol (2010) 11(10):889-96. doi:10.1038/ni.1937

27. Ginhoux F, Schultze JL, Murray PJ, Ochando J, Biswas SK. New insights into the multidimensional concept of macrophage ontogeny, activation and function. Nat Immunol (2016) 17(1):34-40. doi:10.1038/ni.3324

28. Kumar V, Cheng P, Condamine T, Mony S, Languino LR, McCaffrey JC, et al. CD45 phosphatase inhibits STAT3 transcription factor activity in myeloid cells and promotes tumor-associated macrophage differentiation. Immunity (2016) 44(2):303-15. doi:10.1016/j.immuni.2016.01.014

29. Noy R, Pollard JW. Tumor-associated macrophages: from mechanisms to therapy. Immunity (2014) 41(1):49-61. doi:10.1016/j.immuni.2014.06.010

30. Ruffell B, Affara NI, Coussens LM. Differential macrophage programming in the tumor microenvironment. Trends Immunol (2012) 33(3):119-26. doi:10.1016/j.it.2011.12.001

31. Leek RD, Landers R, Fox SB, Ng F, Harris AL, Lewis CE. Association of tumour necrosis factor alpha and its receptors with thymidine phosphorylase expression in invasive breast carcinoma. Br J Cancer (1998) 77(12):2246-51. doi:10.1038/bjc.1998.373

32. Riabov V, Gudima A, Wang N, Mickley A, Orekhov A, Kzhyshkowska J. Role of tumor associated macrophages in tumor angiogenesis and lymphangiogenesis. Front Physiol (2014) 5:75. doi:10.3389/fphys.2014.00075

33. Sierra JR, Corso S, Caione L, Cepero V, Conrotto P, Cignetti A, et al. Tumor angiogenesis and progression are enhanced by Sema4D produced by tumor-associated macrophages. JExp Med (2008) 205(7):1673-85. doi:10.1084/jem.20072602

34. Zhou H, Binmadi NO, Yang YH, Proia P, Basile JR. Semaphorin 4 D cooperates with VEGF to promote angiogenesis and tumor progression. Angiogenesis (2012) 15(3):391-407. doi:10.1007/s10456-012-9268-y

35. Gomes FG, Nedel F, Alves AM, Nör JE, Tarquinio SB. Tumor angiogenesis and lymphangiogenesis: tumor/endothelial crosstalk and cellular/microenvironmental signaling mechanisms. Life Sci (2013) 92(2):101-7. doi:10.1016/j. lfs.2012.10.008

36. Ran S, Montgomery KE. Macrophage-mediated lymphangiogenesis: the emerging role of macrophages as lymphatic endothelial progenitors. Cancers (Basel) (2012) 4(3):618-57. doi:10.3390/cancers4030618

37. Spiric Z, Eri Z, Eric M. Significance of vascular endothelial growth factor (VEGF)-C and VEGF-D in the progression of cutaneous melanoma. Int J Surg Pathol (2015) 23(8):629-37. doi:10.1177/1066896915583694

38. Nagakawa Y, Aoki T, Kasuya K, Tsuchida A, Koyanagi Y. Histologic features of venous invasion, expression of vascular endothelial growth factor and matrix metalloproteinase- 2 and matrix metalloproteinase- 9 , and the relation with liver metastasis in pancreatic cancer. Pancreas (2002) 24(2):169-78. doi:10.1097/00006676-200203000-00008

39. Sevenich L, Bowman RL, Mason SD, Quail DF, Rapaport F, Elie BT, et al. Analysis of tumour- and stroma-supplied proteolytic networks reveals a brain-metastasis-promoting role for cathepsin S. Nat Cell Biol (2014) 16(9):876-88. doi:10.1038/ncb3011

40. Zhang J, Sud S, Mizutani K, Gyetko MR, Pienta KJ. Activation of urokinase plasminogen activator and its receptor axis is essential for macrophage infiltration in a prostate cancer mouse model. Neoplasia (2011) 13(1):23-30. doi:10.1593/neo.10728

41. Yang C, He L, He P, Liu Y, Wang W, He Y, et al. Increased drug resistance in breast cancer by tumor-associated macrophages through IL-10/STAT3/ bcl-2 signaling pathway. Med Oncol (2015) 32(2):352. doi:10.1007/s12032014-0352-6
42. Chung FT, Lee KY, Wang CW, Heh CC, Chan YF, Chen HW, et al. Tumorassociated macrophages correlate with response to epidermal growth factor receptor-tyrosine kinase inhibitors in advanced non-small cell lung cancer. Int J Cancer (2012) 131(3):E227-35. doi:10.1002/ijc.27403

43. Zhang B, Zhang Y, Zhao J, Wang Z, Wu T, Ou W, et al. M2-polarized macrophages contribute to the decreased sensitivity of EGFR-TKIs treatment in patients with advanced lung adenocarcinoma. Med Oncol (2014) 31(8):127. doi:10.1007/s12032-014-0127-0

44. Hughes R, Qian BZ, Rowan C, Muthana M, Keklikoglou I, Olson OC, et al. Perivascular M2 macrophages stimulate tumor relapse after chemotherapy. Cancer Res (2015) 75(17):3479-91. doi:10.1158/0008-5472.CAN14-3587

45. Mazzieri R, Pucci F, Moi D, Zonari E, Ranghetti A, Berti A, et al. Targeting the ANG2/TIE2 axis inhibits tumor growth and metastasis by impairing angiogenesis and disabling rebounds of proangiogenic myeloid cells. Cancer Cell (2011) 19(4):512-26. doi:10.1016/j.ccr.2011.02.005

46. Palucka AK, Coussens LM. The basis of oncoimmunology. Cell (2016) 164(6):1233-47. doi:10.1016/j.cell.2016.01.049

47. Mortara L, Benest AV, Bates DO, Noonan DM. Can the co-dependence of the immune system and angiogenesis facilitate pharmacological targeting of tumours? Curr Opin Pharmacol (2017) 35:66-74. doi:10.1016/j.coph. 2017.05.009

48. Liu J, Zhang N, Li Q, Zhang W, Ke F, Leng Q, et al. Tumor-associated macrophages recruit CCR6+ regulatory $\mathrm{T}$ cells and promote the development of colorectal cancer via enhancing CCL20 production in mice. PLoS One (2011) 6(4):e19495. doi:10.1371/journal.pone.0019495

49. Curiel TJ, Coukos G, Zou L, Alvarez X, Cheng P, Mottram P, et al. Specific recruitment of regulatory $\mathrm{T}$ cells in ovarian carcinoma fosters immune privilege and predicts reduced survival. Nat Med (2004) 10(9):942-9. doi:10.1038/ nm 1093

50. Costa-Silva B, Aiello NM, Ocean AJ, Singh S, Zhang H, Thakur BK, et al. Pancreatic cancer exosomes initiate pre-metastatic niche formation in the liver. Nat Cell Biol (2015) 17(6):816-26. doi:10.1038/ncb3169

51. Gil-Bernabé AM, Ferjancic S, Tlalka M, Zhao L, Allen PD, Im JH, et al. Recruitment of monocytes/macrophages by tissue factor-mediated coagulation is essential for metastatic cell survival and premetastatic niche establishment in mice. Blood (2012) 119(13):3164-75. doi:10.1182/ blood-2011-08-376426

52. Zheng X, Turkowski K, Mora J, Brüne B, Seeger W, Weigert A, et al. Redirecting tumor-associated macrophages to become tumoricidal effectors as a novel strategy for cancer therapy. Oncotarget (2017) 8(29):48436-52. doi:10.18632/oncotarget.17061

53. Li X, Yao W, Yuan Y, Chen P, Li B, Li J, et al. Targeting of tumour-infiltrating macrophages via CCL2/CCR2 signalling as a therapeutic strategy against hepatocellular carcinoma. Gut (2017) 66(1):157-67. doi:10.1136/ gutjnl-2015-310514

54. Loberg RD, Ying C, Craig M, Day LL, Sargent E, Neeley C, et al. Targeting CCL2 with systemic delivery of neutralizing antibodies induces prostate cancer tumor regression in vivo. Cancer Res (2007) 67(19):9417-24. doi:10.1158/ 0008-5472.CAN-07-1286

55. U.S. National Library of Medicine. ClinicalTrials.gov. (2017). Available from: https://clinicaltrials.gov/ct2/results?term=CCL2+cancer\&age_v=\&gndr=\&typ $\mathrm{e}=\& \mathrm{rslt}=\&$ phase $=0$ \&phase $=1 \&$ Search $=$ Apply

56. Halama N, Zoernig I, Berthel A, Kahlert C, Klupp F, Suarez-Carmona M, et al. Tumoral immune cell exploitation in colorectal cancer metastases can be targeted effectively by anti-CCR 5 therapy in cancer patients. Cancer Cell (2016) 29(4):587-601. doi:10.1016/j.ccell.2016.03.005

57. Ries CH, Cannarile MA, Hoves S, Benz J, Wartha K, Runza V, et al. Targeting tumor-associated macrophages with anti-CSF-1R antibody reveals a strategy for cancer therapy. Cancer Cell (2014) 25(6):846-59. doi:10.1016/j.ccr.2014. 05.016

58. Cassier PA, Italiano A, Gomez-Roca CA, Le Tourneau C, Toulmonde M, Cannarile MA, et al. CSF1R inhibition with emactuzumab in locally advanced diffuse-type tenosynovial giant cell tumours of the soft tissue: a dose-escalation and dose-expansion phase 1 study. Lancet Oncol (2015) 16(8):949-56. doi:10.1016/S1470-2045(15)00132-1

59. Pyonteck SM, Akkari L, Schuhmacher AJ, Bowman RL, Sevenich L, Quail DF, et al. CSF-1R inhibition alters macrophage polarization and blocks glioma progression. Nat Med (2013) 19(10):1264-72. doi:10.1038/nm.3337 
60. Junankar S, Shay G, Jurczyluk J, Ali N, Down J, Pocock N, et al. Realtime intravital imaging establishes tumor-associated macrophages as the extraskeletal target of bisphosphonate action in cancer. Cancer Discov (2015) 5(1):35-42. doi:10.1158/2159-8290.CD-14-0621

61. Van Acker HH, Anguille S, Willemen Y, Smits EL, Van Tendeloo VF. Bisphosphonates for cancer treatment: mechanisms of action and lessons from clinical trials. Pharmacol Ther (2016) 158:24-40. doi:10.1016/j. pharmthera.2015.11.008

62. Beatty GL, Chiorean EG, Fishman MP, Saboury B, Teitelbaum UR, Sun W, et al. CD40 agonists alter tumor stroma and show efficacy against pancreatic carcinoma in mice and humans. Science (2011) 331(6024):1612-6. doi:10.1126/science. 1198443

63. Beatty GL, Torigian DA, Chiorean EG, Saboury B, Brothers A, Alavi A, et al. A phase I study of an agonist CD40 monoclonal antibody (CP-870,893) in combination with gemcitabine in patients with advanced pancreatic ductal adenocarcinoma. Clin Cancer Res (2013) 19(22):6286-95. doi:10.1158/10780432.CCR-13-1320

64. Allavena P, Germano G, Belgiovine C, D’Incalci M, Mantovani A. Trabectedin: a drug from the sea that strikes tumor-associated macrophages. Oncoimmunology (2013) 2(6):e24614. doi:10.4161/onci.24614

65. Germano G, Frapolli R, Belgiovine C, Anselmo A, Pesce S, Liguori M, et al. Role of macrophage targeting in the antitumor activity of trabectedin. Cancer Cell (2013) 23(2):249-62. doi:10.1016/j.ccr.2013.01.008

66. Kolaczkowska E, Kubes P. Neutrophil recruitment and function in health and inflammation. Nat Rev Immunol (2013) 13(3):159-75. doi:10.1038/ nri3399

67. Tecchio C, Scapini P, Pizzolo G, Cassatella MA. On the cytokines produced by human neutrophils in tumors. Semin Cancer Biol (2013) 23(3):159-70. doi:10.1016/j.semcancer.2013.02.004

68. Donskov F. Immunomonitoring and prognostic relevance of neutrophils in clinical trials. Semin Cancer Biol (2013) 23(3):200-7. doi:10.1016/j. semcancer.2013.02.001

69. Galdiero MR, Bianchi P, Grizzi F, Di Caro G, Basso G, Ponzetta A, et al. Occurrence and significance of tumor-associated neutrophils in patients with colorectal cancer. Int J Cancer (2016) 139(2):446-56. doi:10.1002/ijc. 30076

70. Jensen HK, Donskov F, Marcussen N, Nordsmark M, Lundbeck F, von der Maase $\mathrm{H}$. Presence of intratumoral neutrophils is an independent prognostic factor in localized renal cell carcinoma. J Clin Oncol (2009) 27(28):4709-17. doi:10.1200/JCO.2008.18.9498

71. Kuang DM, Zhao Q, Wu Y, Peng C, Wang J, Xu Z, et al. Peritumoral neutrophils link inflammatory response to disease progression by fostering angiogenesis in hepatocellular carcinoma. J Hepatol (2011) 54(5):948-55. doi:10.1016/j.jhep.2010.08.041

72. Rao HL, Chen JW, Li M, Xiao YB, Fu J, Zeng YX, et al. Increased intratumoral neutrophil in colorectal carcinomas correlates closely with malignant phenotype and predicts patients' adverse prognosis. PLoS One (2012) 7(1):e30806. doi:10.1371/journal.pone.0030806

73. Trellakis S, Bruderek K, Dumitru CA, Gholaman H, Gu X, Bankfalvi A, et al. Polymorphonuclear granulocytes in human head and neck cancer: enhanced inflammatory activity, modulation by cancer cells and expansion in advanced disease. Int J Cancer (2011) 129(9):2183-93. doi:10.1002/ijc. 25892

74. Wislez M, Rabbe N, Marchal J, Milleron B, Crestani B, Mayaud C, et al. Hepatocyte growth factor production by neutrophils infiltrating bronchioloalveolar subtype pulmonary adenocarcinoma: role in tumor progression and death. Cancer Res (2003) 63(6):1405-12.

75. Benelli R, Albini A, Noonan D. Neutrophils and angiogenesis: potential initiators of the angiogenic cascade. In: Cassatella MA, editor. The Neutrophil: An Emerging Regulator of Inflammatory and Immune Response. Basel: Karger (2003). p. 167-81.

76. Benelli R, Morini M, Carrozzino F, Ferrari N, Minghelli S, Santi L, et al. Neutrophils as a key cellular target for angiostatin: implications for regulation of angiogenesis and inflammation. FASEB J (2002) 16(2):267-9. doi:10.1096/ fj.01-0651fje

77. Scapini P, Morini M, Tecchio C, Minghelli S, Di Carlo E, Tanghetti E, et al. CXCL1/macrophage inflammatory protein-2-induced angiogenesis in vivo is mediated by neutrophil-derived vascular endothelial growth factor-A. J Immunol (2004) 172(8):5034-40. doi:10.4049/jimmunol.172.8.5034
78. Scapini P,Nesi L, Morini M, Tanghetti E, Belleri M, Noonan D, et al. Generation of biologically active angiostatin kringle 1-3 by activated human neutrophils. J Immunol (2002) 168(11):5798-804. doi:10.4049/jimmunol.168.11.5798

79. Tazzyman S, Niaz H, Murdoch C. Neutrophil-mediated tumour angiogenesis: subversion of immune responses to promote tumour growth. Semin Cancer Biol (2013) 23(3):149-58. doi:10.1016/j.semcancer.2013.02.003

80. Eruslanov EB, Bhojnagarwala PS, Quatromoni JG, Stephen TL, Ranganathan A, Deshpande C, et al. Tumor-associated neutrophils stimulate $\mathrm{T}$ cell responses in early-stage human lung cancer. J Clin Invest (2014) 124(12):5466-80. doi:10.1172/JCI77053

81. Fridlender ZG, Sun J, Kim S, Kapoor V, Cheng G, Ling L, et al. Polarization of tumor-associated neutrophil phenotype by TGF-beta: "N1" versus "N2" TAN. Cancer Cell (2009) 16(3):183-94. doi:10.1016/j.ccr.2009.06.017

82. Shaul ME, Fridlender ZG. Neutrophils as active regulators of the immune system in the tumor microenvironment. J Leukoc Biol (2017) 102(2):343-9. doi:10.1189/jlb.5MR1216-508R

83. Jablonska J, Leschner S, Westphal K, Lienenklaus S, Weiss S. Neutrophils responsive to endogenous IFN-beta regulate tumor angiogenesis and growth in a mouse tumor model. J Clin Invest (2010) 120(4):1151-64. doi:10.1172/ JCI37223

84. Andzinski L, KasnitzN, StahnkeS, Wu CF, Gereke M, von Köckritz-Blickwede M, et al. Type I IFNs induce anti-tumor polarization of tumor associated neutrophils in mice and human. Int J Cancer (2016) 138(8):1982-93. doi:10.1002/ ijc. 29945

85. Liang W, Ferrara N. The complex role of neutrophils in tumor angiogenesis and metastasis. Cancer Immunol Res (2016) 4(2):83-91. doi:10.1158/23266066.CIR-15-0313

86. Shojaei F, Wu X, Zhong C, Yu L, Liang XH, Yao J, et al. Bv8 regulates myeloid-cell-dependent tumour angiogenesis. Nature (2007) 450(7171): 825-31. doi:10.1038/nature06348

87. Qu X, Zhuang G, Yu L, Meng G, Ferrara N. Induction of Bv8 expression by granulocyte colony-stimulating factor in $\mathrm{CD} 11 \mathrm{~b}+\mathrm{Gr} 1+$ cells: key role of Stat3 signaling. J Biol Chem (2012) 287(23):19574-84. doi:10.1074/jbc. M111.326801

88. Kujawski M, Kortylewski M, Lee H, Herrmann A, Kay H, Yu H. Stat3 mediates myeloid cell-dependent tumor angiogenesis in mice. J Clin Invest (2008) 118(10):3367-77. doi:10.1172/JCI35213

89. Coussens LM, Tinkle CL, Hanahan D, Werb Z. MMP-9 supplied by bone marrow-derived cells contributes to skin carcinogenesis. Cell (2000) 103(3):481-90. doi:10.1016/S0092-8674(00)00139-2

90. Nozawa H, Chiu C, Hanahan D. Infiltrating neutrophils mediate the initial angiogenic switch in a mouse model of multistage carcinogenesis. Proc Natl Acad Sci U S A (2006) 103(33):12493-8. doi:10.1073/pnas.0601807103

91. Ardi VC, Kupriyanova TA, Deryugina EI, Quigley JP. Human neutrophils uniquely release TIMP-free MMP-9 to provide a potent catalytic stimulator of angiogenesis. Proc Natl Acad Sci U S A (2007) 104(51):20262-7. doi:10.1073/ pnas.0706438104

92. Kaipainen A, Kieran MW, Huang S, Butterfield C, Bielenberg D, Mostoslavsky G, et al. PPARalpha deficiency in inflammatory cells suppresses tumor growth. PLoS One (2007) 2(2):e260. doi:10.1371/journal.pone.0000260

93. Loffredo S, Borriello F, Iannone R, Ferrara AL, Galdiero MR, Gigantino V, et al. Group V secreted phospholipase A2 induces the release of proangiogenic and antiangiogenic factors by human neutrophils. Front Immunol (2017) 8:443. doi:10.3389/fimmu.2017.00443

94. Kikuchi R, Nakamura K, MacLauchlan S, Ngo DT, Shimizu I, Fuster JJ, et al. An antiangiogenic isoform of VEGF-A contributes to impaired vascularization in peripheral artery disease. Nat Med (2014) 20(12):1464-71. doi: $10.1038 / \mathrm{nm} .3703$

95. Deryugina EI, Zajac E, Juncker-Jensen A, Kupriyanova TA, Welter L, Quigley JP. Tissue-infiltrating neutrophils constitute the major in vivo source of angiogenesis-inducing MMP-9 in the tumor microenvironment. Neoplasia (2014) 16(10):771-88. doi:10.1016/j.neo.2014.08.013

96. Cools-Lartigue J, Spicer J, McDonald B, Gowing S, Chow S, Giannias B, et al. Neutrophil extracellular traps sequester circulating tumor cells and promote metastasis. J Clin Invest (2013) 123(8):3446-58. doi:10.1172/JCI67484

97. Gordon-Weeks AN, Lim SY, Yuzhalin AE, Jones K, Markelc B, Kim KJ, et al. Neutrophils promote hepatic metastasis growth through fibroblast growth factor 2-dependent angiogenesis in mice. Hepatology (2017) 65(6):1920-35. doi:10.1002/hep.29088 
98. Steele CW, Karim SA, Leach JDG, Bailey P, Upstill-Goddard R, Rishi L, et al. CXCR2 inhibition profoundly suppresses metastases and augments immunotherapy in pancreatic ductal adenocarcinoma. Cancer Cell (2016) 29(6):832-45. doi:10.1016/j.ccell.2016.04.014

99. Tabariès S, Ouellet V, Hsu BE, Annis MG, Rose AA, Meunier L, et al. Granulocytic immune infiltrates are essential for the efficient formation of breast cancer liver metastases. Breast Cancer Res (2015) 17:45. doi:10.1186/ s13058-015-0558-3

100. Rivera LB, Meyronet D, Hervieu V, Frederick MJ, Bergsland E, Bergers G. Intratumoral myeloid cells regulate responsiveness and resistance to antiangiogenic therapy. Cell Rep (2015) 11(4):577-91. doi:10.1016/j.celrep.2015. 03.055

101. Ma Y, Shurin GV, Gutkin DW, Shurin MR. Tumor associated regulatory dendritic cells. Semin Cancer Biol (2012) 22(4):298-306. doi:10.1016/j. semcancer.2012.02.010

102. Shurin GV, Ma Y, Shurin MR. Immunosuppressive mechanisms of regulatory dendritic cells in cancer. Cancer Microenviron (2013) 6(2):159-67. doi:10.1007/s12307-013-0133-3

103. Marvel D, Gabrilovich DI. Myeloid-derived suppressor cells in the tumor microenvironment: expect the unexpected. J Clin Invest (2015) 125(9):3356-64. doi:10.1172/JCI80005

104. Talmadge JE, Gabrilovich DI. History of myeloid-derived suppressor cells. Nat Rev Cancer (2013) 13(10):739-52. doi:10.1038/nrc3581

105. Ugel S, De Sanctis F, Mandruzzato S, Bronte V. Tumor-induced myeloid deviation: when myeloid-derived suppressor cells meet tumor-associated macrophages. J Clin Invest (2015) 125(9):3365-76. doi:10.1172/JCI80006

106. Kumar V, Patel S, Tcyganov E, Gabrilovich DI. The nature of myeloid-derived suppressor cells in the tumor microenvironment. Trends Immunol (2016) 37(3):208-20. doi:10.1016/j.it.2016.01.004

107. Motz GT, Coukos G. The parallel lives of angiogenesis and immunosuppression: cancer and other tales. Nat Rev Immunol (2011) 11(10):702-11. doi:10.1038/nri3064

108. Maruo Y, Konno H, Baba S. Therapeutic effects of liposomal adriamycin in combination with tumor necrosis factor-alpha. JSurg Oncol (1992) 49(1):20-4. doi:10.1002/jso.2930490106

109. Murdoch C, Muthana M, Coffelt SB, Lewis CE. The role of myeloid cells in the promotion of tumour angiogenesis. Nat Rev Cancer (2008) 8(8):618-31. doi: $10.1038 / \mathrm{nrc} 2444$

110. Porta C, Sica A, Riboldi E. Tumor-associated myeloid cells: new understandings on their metabolic regulation and their influence in cancer immunotherapy. FEBS J (2018) 285(4):717-33. doi:10.1111/febs.14288

111. Sica A, Strauss L, Consonni FM, Travelli C, Genazzani A, Porta C, et al. Metabolic regulation of suppressive myeloid cells in cancer. Cytokine Growth Factor Rev (2017) 35:27-35. doi:10.1016/j.cytogfr.2017.05.002

112. Sica A, Strauss L. Energy metabolism drives myeloid-derived suppressor cell differentiation and functions in pathology. J Leukoc Biol (2017) 102(2): 325-34. doi:10.1189/jlb.4MR1116-476R

113. Hossain F, Al-Khami AA, Wyczechowska D, Hernandez C, Zheng L, Reiss K, et al. Inhibition of fatty acid oxidation modulates immunosuppressive functions of myeloid-derived suppressor cells and enhances cancer therapies. Cancer Immunol Res (2015) 3(11):1236-47. doi:10.1158/2326-6066. CIR-15-0036

114. Park J, Lee SE, Hur J, Hong EB, Choi JI, Yang JM, et al. M-CSF from cancer cells induces fatty acid synthase and PPARbeta/delta activation in tumor myeloid cells, leading to tumor progression. Cell Rep (2015) 10(9):1614-25. doi:10.1016/j.celrep.2015.02.024

115. Kim SH, Li M, Trousil S, Zhang Y, Pasca di Magliano M, Swanson KD, et al. Phenformin inhibits myeloid-derived suppressor cells and enhances the anti-tumor activity of PD-1 blockade in melanoma. J Invest Dermatol (2017) 137(8):1740-8. doi:10.1016/j.jid.2017.03.033

116. Gabrilovich DI, Ostrand-Rosenberg S, Bronte V. Coordinated regulation of myeloid cells by tumours. Nat Rev Immunol (2012) 12(4):253-68. doi: $10.1038 /$ nri3175

117. Brencicova E, Jagger AL, Evans HG, Georgouli M, Laios A, Attard Montalto S, et al. Interleukin-10 and prostaglandin E2 have complementary but distinct suppressive effects on toll-like receptor-mediated dendritic cell activation in ovarian carcinoma. PLoS One (2017) 12(4):e0175712. doi:10.1371/journal. pone. 0175712
118. Chae CS, Teran-Cabanillas E, Cubillos-Ruiz JR. Dendritic cell rehab: new strategies to unleash therapeutic immunity in ovarian cancer. Cancer Immunol Immunother (2017) 66(8):969-77. doi:10.1007/s00262-017-1958-2

119. Conejo-Garcia JR, Rutkowski MR, Cubillos-Ruiz JR. State-of-the-art of regulatory dendritic cells in cancer. Pharmacol Ther (2016) 164:97-104. doi:10.1016/j.pharmthera.2016.04.003

120. Herber DL, Cao W, Nefedova Y, Novitskiy SV, Nagaraj S, Tyurin VA, et al. Lipid accumulation and dendritic cell dysfunction in cancer. Nat Med (2010) 16(8):880-6. doi:10.1038/nm.2172

121. Conejo-Garcia JR, Benencia F, Courreges MC, Kang E, Mohamed-Hadley A, Buckanovich RJ, et al. Tumor-infiltrating dendritic cell precursors recruited by a beta-defensin contribute to vasculogenesis under the influence of Vegf-A. Nat Med (2004) 10(9):950-8. doi:10.1038/nm1097

122. Scarlett UK, Rutkowski MR, Rauwerdink AM, Fields J, Escovar-Fadul X, Baird J, et al. Ovarian cancer progression is controlled by phenotypic changes in dendritic cells. J Exp Med (2012) 209(3):495-506. doi:10.1084/jem.20111413

123. Gardner A, Ruffell B. Dendritic cells and cancer immunity. Trends Immunol (2016) 37(12):855-65. doi:10.1016/j.it.2016.09.006

124. Veglia F, Gabrilovich DI. Dendritic cells in cancer: the role revisited. Curr Opin Immunol (2017) 45:43-51. doi:10.1016/j.coi.2017.01.002

125. CrociDO, CerlianiJP,Dalotto-MorenoT,Méndez-HuergoSP, MascanfroniID, Dergan-Dylon S, et al. Glycosylation-dependent lectin-receptor interactions preserve angiogenesis in anti-VEGF refractory tumors. Cell (2014) 156(4):744-58. doi:10.1016/j.cell.2014.01.043

126. Banerjee DK, Dhodapkar MV, Matayeva E, Steinman RM, Dhodapkar KM. Expansion of FOXP3high regulatory T cells by human dendritic cells (DCs) in vitro and after injection of cytokine-matured DCs in myeloma patients. Blood (2006) 108(8):2655-61. doi:10.1182/blood-2006-03-011353

127. Ghiringhelli F, Puig PE, Roux S, Parcellier A, Schmitt E, Solary E, et al. Tumor cells convert immature myeloid dendritic cells into TGF-beta-secreting cells inducing CD4+CD25+ regulatory T cell proliferation. J Exp Med (2005) 202(7):919-29. doi:10.1084/jem.20050463

128. Liu VC, Wong LY, Jang T, Shah AH, Park I, Yang X, et al. Tumor evasion of the immune system by converting CD4+CD25- T cells into CD4+CD25+ $\mathrm{T}$ regulatory cells: role of tumor-derived TGF-beta. J Immunol (2007) 178(5):2883-92. doi:10.4049/jimmunol.178.5.2883

129. Yang M, Ma C, Liu S, Shao Q, Gao W, Song B, et al. HIF-dependent induction of adenosine receptor A2b skews human dendritic cells to a Th2-stimulating phenotype under hypoxia. Immunol Cell Biol (2010) 88(2):165-71. doi:10.1038/ icb. 2009.77

130. Gabrilovich DI. Myeloid-derived suppressor cells. Cancer Immunol Res (2017) 5(1):3-8. doi:10.1158/2326-6066.CIR-16-0297

131. Varricchi G, Galdiero MR, Loffredo S, Marone G, Iannone R, Marone G, et al. Are mast cells MASTers in cancer? Front Immunol (2017) 8:424. doi:10.3389/ fimmu.2017.00424

132. Chan CY, St John AL, Abraham SN. Plasticity in mast cell responses during bacterial infections. Curr Opin Microbiol (2012) 15(1):78-84. doi:10.1016/j. mib.2011.10.007

133. Marichal T, Starkl P, Reber LL, Kalesnikoff J, Oettgen HC, Tsai M, et al. A beneficial role for immunoglobulin $\mathrm{E}$ in host defense against honeybee venom. Immunity (2013) 39(5):963-75. doi:10.1016/j.immuni.2013.10.005

134. Palm NW, Rosenstein RK, Yu S, Schenten DD, Florsheim E, Medzhitov R. Bee venom phospholipase A2 induces a primary type 2 response that is dependent on the receptor ST2 and confers protective immunity. Immunity (2013) 39(5):976-85. doi:10.1016/j.immuni.2013.10.006

135. Wang Z, Lai Y, Bernard JJ, Macleod DT, Cogen AL, Moss B, et al. Skin mast cells protect mice against vaccinia virus by triggering mast cell receptor S1PR2 and releasing antimicrobial peptides. J Immunol (2012) 188(1): 345-57. doi:10.4049/jimmunol.1101703

136. Marone G, Varricchi G, Loffredo S, Granata F. Mast cells and basophils in inflammatory and tumor angiogenesis and lymphangiogenesis. Eur J Pharmacol (2016) 778:146-51. doi:10.1016/j.ejphar.2015.03.088

137. Jachetti E, Rigoni A, Bongiovanni L, Arioli I, Botti L, Parenza M, et al. Imatinib spares cKit-expressing prostate neuroendocrine tumors, whereas kills seminal vesicle epithelial-stromal tumors by targeting PDGFR-beta. Mol Cancer Ther (2017) 16(2):365-75. doi:10.1158/1535-7163.MCT-16-0466

138. Coussens LM, Raymond WW, Bergers G, Laig-Webster M, Behrendtsen $\mathrm{O}$, Werb $\mathrm{Z}$, et al. Inflammatory mast cells up-regulate angiogenesis during 
squamous epithelial carcinogenesis. Genes Dev (1999) 13(11):1382-97. doi:10.1101/gad.13.11.1382

139. de Souza Junior DA, Santana AC, da Silva EZ, Oliver C, Jamur MC. The role of mast cell specific chymases and tryptases in tumor angiogenesis. Biomed Res Int (2015) 2015:142359. doi:10.1155/2015/142359

140. Chen Y, Li C, Xie H, Fan Y, Yang Z, Ma J, et al. Infiltrating mast cells promote renal cell carcinoma angiogenesis by modulating PI3K - >AKT >GSK3beta->AM signaling. Oncogene (2017) 36(20):2879-88. doi:10.1038/ onc. 2016.442

141. Ammendola M, Leporini C, Marech I, Gadaleta CD, Scognamillo G, Sacco R, et al. Targeting mast cells tryptase in tumor microenvironment: a potential antiangiogenetic strategy. Biomed Res Int (2014) 2014:154702. doi:10.1155/2014/154702

142. Ammendola M, Patruno R, Sacco R, Marech I, Sammarco G, Zuccalà V, et al. Mast cells positive to tryptase and tumour-associated macrophages correlate with angiogenesis in locally advanced colorectal cancer patients undergone to surgery. Expert Opin Ther Targets (2016) 20(5):533-40. doi:10.1517/1472 8222.2016.1158811

143. Vyzoukaki R, Tsirakis G, Pappa CA, Androulakis N, Kokonozaki M, Tzardi M, et al. Correlation of mast cell density with angiogenic cytokines in patients with active multiple myeloma. Clin Ther (2016) 38(2):297-301. doi:10.1016/j.clinthera.2015.11.022

144. Nico B, Mangieri D, Crivellato E, Vacca A, Ribatti D. Mast cells contribute to vasculogenic mimicry in multiple myeloma. Stem Cells Dev (2008) 17(1):19-22. doi:10.1089/scd.2007.0132

145. Ammendola M, Sacco R, Sammarco G, Donato G, Montemurro S, Ruggieri E, et al. Correlation between serum tryptase, mast cells positive to tryptase and microvascular density in colo-rectal cancer patients: possible biological-clinical significance. PLoS One (2014) 9(6):e99512. doi:10.1371/journal. pone.0099512

146. Ranieri G, Ammendola M, Patruno R, Celano G, Zito FA, Montemurro S, et al. Tryptase-positive mast cells correlate with angiogenesis in early breast cancer patients. Int J Oncol (2009) 35(1):115-20. doi:10.3892/ijo_ 00000319

147. Patil RS, Bhat SA, Dar AA, Chiplunkar SV. The Jekyll and Hyde story of IL17producing gammadeltaT Cells. Front Immunol (2015) 6:37. doi:10.3389/ fimmu.2015.00037

148. Yang B, Kang H, Fung A, Zhao H, Wang T, Ma D. The role of interleukin 17 in tumour proliferation, angiogenesis, and metastasis. Mediators Inflamm (2014) 2014:623759. doi:10.1155/2014/623759

149. Wu P, Wu D, Ni C, Ye J, Chen W, Hu G, et al. gammadeltaT17 cells promote the accumulation and expansion of myeloid-derived suppressor cells in human colorectal cancer. Immunity (2014) 40(5):785-800. doi:10.1016/j. immuni.2014.03.013

150. Numasaki M, Watanabe M, Suzuki T, Takahashi H, Nakamura A, McAllister F, et al. IL-17 enhances the net angiogenic activity and in vivo growth of human non-small cell lung cancer in SCID mice through promoting CXCR-2dependent angiogenesis. JImmunol (2005) 175(9):6177-89. doi:10.4049/ jimmunol.175.9.6177

151. Qian X, Chen H, Wu X, Hu L, Huang Q, Jin Y. Interleukin-17 acts as double-edged sword in anti-tumor immunity and tumorigenesis. Cytokine (2017) 89:34-44. doi:10.1016/j.cyto.2015.09.011

152. Wakita D, Sumida K, Iwakura Y, Nishikawa H, Ohkuri T, Chamoto K, et al. Tumor-infiltrating IL-17-producing gammadelta T cells support the progression of tumor by promoting angiogenesis. Eur J Immunol (2010) 40(7):1927-37. doi:10.1002/eji.200940157

153. Liu J, Duan Y, Cheng X, Chen X, Xie W, Long H, et al. IL-17 is associated with poor prognosis and promotes angiogenesis via stimulating VEGF production of cancer cells in colorectal carcinoma. Biochem Biophys Res Commun (2011) 407(2):348-54. doi:10.1016/j.bbrc.2011.03.021

154. Pan B, Shen J, Cao J, Zhou Y, Shang L, Jin S, et al. Interleukin-17 promotes angiogenesis by stimulating VEGF production of cancer cells via the STAT3/ GIV signaling pathway in non-small-cell lung cancer. Sci Rep (2015) 5:16053. doi:10.1038/srep16053

155. Patil RS, Shah SU, Shrikhande SV, Goel M, Dikshit RP, Chiplunkar SV, et al. IL17 producing gammadeltaT cells induce angiogenesis and are associated with poor survival in gallbladder cancer patients. Int J Cancer (2016) 139(4):869-81. doi:10.1002/ijc.30134
156. Campbell JJ, Ebsworth K, Ertl LS, McMahon JP, Newland D, Wang Y, et al. IL-17-secreting gammadelta $\mathrm{T}$ cells are completely dependent upon CCR6 for homing to inflamed skin. J Immunol (2017) 199(9):3129-36. doi:10.4049/ jimmunol.1700826

157. Carrega P, Campana S, Bonaccorsi I, Ferlazzo G. The Yin and Yang of innate lymphoid cells in cancer. Immunol Lett (2016) 179:29-35. doi:10.1016/j. imlet.2016.06.003

158. Mattner J, Wirtz S. Friend or foe? The ambiguous role of innate lymphoid cells in cancer development. Trends Immunol (2017) 38(1):29-38. doi:10.1016/j. it.2016.10.004

159. Spits $\mathrm{H}$, Cupedo $\mathrm{T}$. Innate lymphoid cells: emerging insights in development, lineage relationships, and function. Annu Rev Immunol (2012) 30:647-75. doi:10.1146/annurev-immunol-020711-075053

160. Vallentin B, Barlogis V, Piperoglou C, Cypowyj S, Zucchini N, Chéné M, et al. Innate lymphoid cells in cancer. Cancer Immunol Res (2015) 3(10):1109-14. doi:10.1158/2326-6066.CIR-15-0222

161. Mjosberg J, Spits H. Human innate lymphoid cells. J Allergy Clin Immunol (2016) 138(5):1265-76. doi:10.1016/j.jaci.2016.09.009

162. Spits H, Artis D, Colonna M, Diefenbach A, Di Santo JP, Eberl G, et al. Innate lymphoid cells - a proposal for uniform nomenclature. Nat Rev Immunol (2013) 13(2):145-9. doi:10.1038/nri3365

163. Buonocore S, Ahern PP, Uhlig HH, Ivanov II, Littman DR, Maloy KJ, et al. Innate lymphoid cells drive interleukin-23-dependent innate intestinal pathology. Nature (2010) 464(7293):1371-5. doi:10.1038/nature08949

164. Chang YJ, Kim HY, Albacker LA, Baumgarth N, McKenzie AN, Smith DE, et al. Innate lymphoid cells mediate influenza-induced airway hyper-reactivity independently of adaptive immunity. Nat Immunol (2011) 12(7):631-8. doi:10.1038/ni.2045

165. Halim TY, Krauss RH, Sun AC, Takei F. Lung natural helper cells are a critical source of Th2 cell-type cytokines in protease allergen-induced airway inflammation. Immunity (2012) 36(3):451-63. doi:10.1016/j.immuni.2011.12.020

166. Kim BS, Siracusa MC, Saenz SA, Noti M, Monticelli LA, Sonnenberg GF, et al. TSLP elicits IL-33-independent innate lymphoid cell responses to promote skin inflammation. Sci Transl Med (2013) 5(170):170ra16. doi:10.1126/ scitranslmed.3005374

167. McHedlidze T, Waldner M, Zopf S, Walker J, Rankin AL, Schuchmann M, et al. Interleukin-33-dependent innate lymphoid cells mediate hepatic fibrosis. Immunity (2013) 39(2):357-71. doi:10.1016/j.immuni.2013.07.018

168. Roediger B, Kyle R, Yip KH, Sumaria N, Guy TV, Kim BS, et al. Cutaneous immunosurveillance and regulation of inflammation by group 2 innate lymphoid cells. Nat Immunol (2013) 14(6):564-73. doi:10.1038/ni.2584

169. Hazenberg MD, Spits H. Human innate lymphoid cells. Blood (2014) 124(5):700-9. doi:10.1182/blood-2013-11-427781

170. Dadi S, Chhangawala S, Whitlock BM, Franklin RA, Luo CT, Oh SA, et al. Cancer immunosurveillance by tissue-resident innate lymphoid cells and innate-like T cells. Cell (2016) 164(3):365-77. doi:10.1016/j.cell.2016.01.002

171. van Beek JJP, Martens AWJ, Bakdash G, de Vries IJM. Innate lymphoid cells in tumor immunity. Biomedicines (2016) 4(1):E7. doi:10.3390/ biomedicines 4010007

172. Jovanovic IP, Pejnovic NN, Radosavljevic GD, Pantic JM, Milovanovic MZ, Arsenijevic NN, et al. Interleukin-33/ST2 axis promotes breast cancer growth and metastases by facilitating intratumoral accumulation of immunosuppressive and innate lymphoid cells. Int J Cancer (2014) 134(7):1669-82. doi:10.1002/ijc.28481

173. Geremia A, Arancibia-Cárcamo CV, Fleming MP, Rust N, Singh B, Mortensen NJ, et al. IL-23-responsive innate lymphoid cells are increased in inflammatory bowel disease. J Exp Med (2011) 208(6):1127-33. doi:10.1084/ jem. 20101712

174. Chen X, Xie Q, Cheng X, Diao X, Cheng Y, Liu J, et al. Role of interleukin-17 in lymphangiogenesis in non-small-cell lung cancer: enhanced production of vascular endothelial growth factor $\mathrm{C}$ in non-small-cell lung carcinoma cells. Cancer Sci (2010) 101(11):2384-90. doi:10.1111/j.1349-7006.2010.01684.x

175. Huang Q, Duan L, Qian X, Fan J, Lv Z, Zhang X, et al. IL-17 promotes angiogenic factors IL-6, IL-8, and Vegf production via Stat1 in lung adenocarcinoma. Sci Rep (2016) 6:36551. doi:10.1038/srep36551

176. Numasaki M, Fukushi J, Ono M, Narula SK, Zavodny PJ, Kudo T, et al. Interleukin-17 promotes angiogenesis and tumor growth. Blood (2003) 101(7):2620-7. doi:10.1182/blood-2002-05-1461 
177. He D, Li H, Yusuf N, Elmets CA, Li J, Mountz JD, et al. IL-17 promotes tumor development through the induction of tumor promoting microenvironments at tumor sites and myeloid-derived suppressor cells. J Immunol (2010) 184(5):2281-8. doi:10.4049/jimmunol.0902574

178. Li Q, Liu L, Zhang Q, Liu S, Ge D, You Z. Interleukin-17 indirectly promotes M2 macrophage differentiation through stimulation of COX-2/PGE2 pathway in the cancer cells. Cancer Res Treat (2014) 46(3):297-306. doi:10.4143/ crt.2014.46.3.297

179. Kirchberger S, Royston DJ, Boulard O, Thornton E, Franchini F, Szabady RL, et al. Innate lymphoid cells sustain colon cancer through production of interleukin-22 in a mouse model. J Exp Med (2013) 210(5):917-31. doi:10.1084/jem.20122308

180. Irshad S, Flores-Borja F, Lawler K, Monypenny J, Evans R, Male V, et al. RORgammat(+) innate lymphoid cells promote lymph node metastasis of breast cancers. Cancer Res (2017) 77(5):1083-96. doi:10.1158/ 0008-5472.CAN-16-0598

181. Tian Z, van Velkinburgh JC, Wu Y, Ni B. Innate lymphoid cells involve in tumorigenesis. Int J Cancer (2016) 138(1):22-9. doi:10.1002/ijc.29443

182. Figenschau SL, Fismen S, Fenton KA, Fenton C, Mortensen ES. Tertiary lymphoid structures are associated with higher tumor grade in primary operable breast cancer patients. BMC Cancer (2015) 15:101. doi:10.1186/ s12885-015-1116-1

183. Sautès-Fridman C, Lawand M, Giraldo NA, Kaplon H, Germain C, Fridman WH, et al. Tertiary lymphoid structures in cancers: prognostic value, regulation, and manipulation for therapeutic intervention. Front Immunol (2016) 7:407. doi:10.3389/fimmu.2016.00407

184. Shields JD, Kourtis IC, Tomei AA, Roberts JM, Swartz MA. Induction of lymphoidlike stroma and immune escape by tumors that express the chemokine CCL21. Science (2010) 328(5979):749-52. doi:10.1126/science.1185837

185. Carrega P, Loiacono F, Di Carlo E, Scaramuccia A, Mora M, Conte R, et al. NCR(+)ILC3 concentrate in human lung cancer and associate with intratumoral lymphoid structures. Nat Commun (2015) 6:8280. doi:10.1038/ ncomms 9280

186. Shikhagaie MM, Björklund ÅK, Mjösberg J, Erjefält JS, Cornelissen AS, Ros XR, et al. Neuropilin-1 is expressed on lymphoid tissue residing LTilike group 3 innate lymphoid cells and associated with ectopic lymphoid aggregates. Cell Rep (2017) 18(7):1761-73. doi:10.1016/j.celrep.2017.01.063

187. Cooper MA, Fehniger TA, Caligiuri MA. The biology of human natural killer-cell subsets. Trends Immunol (2001) 22(11):633-40. doi:10.1016/ S1471-4906(01)02060-9

188. De Maria A, Bozzano F, Cantoni C, Moretta L. Revisiting human natural killer cell subset function revealed cytolytic CD56(dim)CD16+ NK cells as rapid producers of abundant IFN-gamma on activation. Proc Natl Acad Sci US A (2011) 108(2):728-32. doi:10.1073/pnas.1012356108

189. Fauriat C, Long EO, Ljunggren HG, Bryceson YT. Regulation of human NK-cell cytokine and chemokine production by target cell recognition. Blood (2010) 115(11):2167-76. doi:10.1182/blood-2009-08-238469

190. Cantoni C, Huergo-Zapico L, Parodi M, Pedrazzi M, Mingari MC, Moretta A, et al. NK cells, tumor cell transition, and tumor progression in solid malignancies: new hints for NK-based immunotherapy? J Immunol Res (2016) 2016:4684268. doi:10.1155/2016/4684268

191. Narni-Mancinelli E, Vivier E, Kerdiles YM. The 'T-cell-ness' of NK cells: unexpected similarities between NK cells and T cells. Int Immunol (2011) 23(7):427-31. doi:10.1093/intimm/dxr035

192. Vitale M, Cantoni C, Pietra G, Mingari MC, Moretta L. Effect of tumor cells and tumor microenvironment on NK-cell function. Eur J Immunol (2014) 44(6):1582-92. doi:10.1002/eji.201344272

193. Zhang J, Marotel M, Fauteux-Daniel S, Mathieu AL, Viel S, Marçais A, et al. T-bet and Eomes govern differentiation and function of mouse and human NK cells and ILC1. Eur J Immunol (2018). doi:10.1002/eji.201747299

194. Del Zotto G, Marcenaro E, Vacca P, Sivori S, Pende D, Della Chiesa M, et al. Markers and function of human NK cells in normal and pathological conditions. Cytometry B Clin Cytom (2017) 92(2):100-14. doi:10.1002/cyto. b. 21508

195. Della Chiesa M, Pesce S, Muccio L, Carlomagno S, Sivori S, Moretta A, et al. Features of memory-like and PD-1(+) human NK cell subsets. Front Immunol (2016) 7:351. doi:10.3389/fimmu.2016.00351

196. Molgora M, Bonavita E, Ponzetta A, Riva F, Barbagallo M, Jaillon S, et al. IL$1 \mathrm{R} 8$ is a checkpoint in NK cells regulating anti-tumour and anti-viral activity. Nature (2017) 551(7678):110-4. doi:10.1038/nature24293
197. Putz EM, Guillerey C, Kos K, Stannard K, Miles K, Delconte RB, et al. Targeting cytokine signaling checkpoint CIS activates NK cells to protect from tumor initiation and metastasis. Oncoimmunology (2017) 6(2):e1267892. doi:10.1080/ 2162402X.2016.1267892

198. Le Bouteiller P, Tabiasco J. Killers become builders during pregnancy. Nat Med (2006) 12(9):991-2. doi:10.1038/nm0906-991

199. Hanna J, Goldman-Wohl D, Hamani Y, Avraham I, Greenfield C, NatansonYaron S, et al. Decidual NK cells regulate key developmental processes at the human fetal-maternal interface. Nat Med (2006) 12(9):1065-74. doi:10.1038/ $\mathrm{nm} 1452$

200. Hanna J, Mandelboim O. When killers become helpers. Trends Immunol (2007) 28(5):201-6. doi:10.1016/j.it.2007.03.005

201. Blois SM, Klapp BF, Barrientos G. Decidualization and angiogenesis in early pregnancy: unravelling the functions of DC and NK cells. J Reprod Immunol (2011) 88:86-92. doi:10.1016/j.jri.2010.11.002

202. Santoni A, Zingoni A, Cerboni C, Gismondi A. Natural killer (NK) cells from killers to regulators: distinct features between peripheral blood and decidual NK cells. Am J Reprod Immunol (2007) 58(3):280-8. doi:10.1111/j.1600-0897.2007.00513.x

203. Baginska J, Viry E, Paggetti J, Medves S, Berchem G, Moussay E, et al. The critical role of the tumor microenvironment in shaping natural killer cell-mediated anti-tumor immunity. Front Immunol (2013) 4:490. doi:10.3389/ fimmu.2013.00490

204. Bruno A, Focaccetti C, Pagani A, Imperatori AS, Spagnoletti M, Rotolo N, et al. The proangiogenic phenotype of natural killer cells in patients with non-small cell lung cancer. Neoplasia (2013) 15(2):133-42. doi:10.1593/neo. 121758

205. Allan DS, Rybalov B, Awong G, Zúñiga-Pflücker JC, Kopcow HD, Carlyle JR, et al. TGF-beta affects development and differentiation of human natural killer cell subsets. Eur J Immunol (2010) 40(8):2289-95. doi:10.1002/ eji.200939910

206. Keskin DB, Allan DS, Rybalov B, Andzelm MM, Stern JN, Kopcow HD, et al. TGFbeta promotes conversion of CD16+ peripheral blood NK cells into CD16- NK cells with similarities to decidual NK cells. Proc Natl Acad Sci U S A (2007) 104(9):3378-83. doi:10.1073/pnas.0611098104

207. Cerdeira AS, Rajakumar A, Royle CM, Lo A, Husain Z, Thadhani RI, et al. Conversion of peripheral blood NK cells to a decidual NK-like phenotype by a cocktail of defined factors. J Immunol (2013) 190(8):3939-48. doi:10.4049/ jimmunol.1202582

208. Gao Y, Souza-Fonseca-Guimaraes F, Bald T, Ng SS, Young A, Ngiow SF, et al. Tumor immunoevasion by the conversion of effector NK cells into type 1 innate lymphoid cells. Nat Immunol (2017) 18(9):1004-15. doi:10.1038/ ni. 3800

209. Schito L, Semenza GL. Hypoxia-inducible factors: master regulators of cancer progression. Trends Cancer (2016) 2(12):758-70. doi:10.1016/j.trecan. 2016.10.016

210. Krzywinska E, Kantari-Mimoun C, Kerdiles Y, Sobecki M, Isagawa T, Gotthardt D, et al. Loss of HIF-1alpha in natural killer cells inhibits tumour growth by stimulating non-productive angiogenesis. Nat Commun (2017) 8(1):1597. doi:10.1038/s41467-017-01599-w

211. Gotthardt D, Putz EM, Grundschober E, Prchal-Murphy M, Straka E, Kudweis P, et al. STAT5 is a key regulator in NK cells and acts as a molecular switch from tumor surveillance to tumor promotion. Cancer Discov (2016) 6(4):414-29. doi:10.1158/2159-8290.CD-15-0732

212. Hoeres T, Wilhelm M, Smetak M, Holzmann E, Schulze-Tanzil G, Birkmann $\mathrm{J}$, et al. Immune cells regulate VEGF signaling via release of VEGF and antagonistic soluble VEGF receptor-1. Clin Exp Immunol (2018) 192(1):54-67. doi: $10.1111 /$ cei. 13090

213. Whiteside TL, Demaria S, Rodriguez-Ruiz ME, Zarour HM, Melero I. Emerging opportunities and challenges in cancer immunotherapy. Clin Cancer Res (2016) 22(8):1845-55. doi:10.1158/1078-0432.CCR-16-0049

214. Lesokhin AM, Callahan MK, Postow MA, Wolchok JD. On being less tolerant: enhanced cancer immunosurveillance enabled by targeting checkpoints and agonists of T cell activation. Sci Transl Med (2015) 7(280):280sr1. doi:10.1126/scitranslmed.3010274

215. Winograd R, Byrne KT, Evans RA, Odorizzi PM, Meyer AR, Bajor DL, et al. Induction of T-cell immunity overcomes complete resistance to PD-1 and CTLA-4 blockade and improves survival in pancreatic carcinoma. Cancer Immunol Res (2015) 3(4):399-411. doi:10.1158/2326-6066.CIR-14-0215 
216. Gopalakrishnan V, Spencer CN, Nezi L, Reuben A, Andrews MC, Karpinets TV, et al. Gut microbiome modulates response to anti-PD-1 immunotherapy in melanoma patients. Science (2018) 359(6371):97-103. doi:10.1126/science. aan 4236

217. Routy B, Le Chatelier E, Derosa L, Duong CPM, Alou MT, Daillère R, et al. Gut microbiome influences efficacy of PD-1-based immunotherapy against epithelial tumors. Science (2018) 359(6371):91-7. doi:10.1126/science. aan3706

218. Zitvogel L, Daillère R, Roberti MP, Routy B, Kroemer G. Anticancer effects of the microbiome and its products. Nat Rev Microbiol (2017) 15(8):465-78. doi:10.1038/nrmicro.2017.44

219. Garrett WS. Cancer and the microbiota. Science (2015) 348(6230):80-6. doi:10.1126/science.aaa4972

220. Dirkx AE, oude Egbrink MG, Castermans K, van der Schaft DW, Thijssen VL, Dings RP, et al. Anti-angiogenesis therapy can overcome endothelial cell anergy and promote leukocyte-endothelium interactions and infiltration in tumors. FASEB J (2006) 20(6):621-30. doi:10.1096/fj.05-4493com

221. Ohm JE, Carbone DP. VEGF as a mediator of tumor-associated immunodeficiency. Immunol Res (2001) 23(2-3):263-72. doi:10.1385/IR:23:2-3:263

222. Voron T, Colussi O, Marcheteau E, Pernot S, Nizard M, Pointet AL, et al. VEGF-A modulates expression of inhibitory checkpoints on CD8+ T cells in tumors. J Exp Med (2015) 212(2):139-48. doi:10.1084/jem.20140559

223. Ebos JM, Kerbel RS. Antiangiogenic therapy: impact on invasion, disease progression, and metastasis. Nat Rev Clin Oncol (2011) 8(4):210-21. doi:10.1038/nrclinonc.2011.21

224. Voron T, Marcheteau E, Pernot S, Colussi O, Tartour E, Taieb J, et al. Control of the immune response by pro-angiogenic factors. Front Oncol (2014) 4:70. doi:10.3389/fonc.2014.00070

225. Allegrezza MJ, Conejo-Garcia JR. Targeted therapy and immunosuppression in the tumor microenvironment. Trends Cancer (2017) 3(1):19-27. doi:10.1016/j.trecan.2016.11.009

226. Pitt JM, Marabelle A, Eggermont A, Soria JC, Kroemer G, Zitvogel L. Targeting the tumor microenvironment: removing obstruction to anticancer immune responses and immunotherapy. Ann Oncol (2016) 27(8):1482-92. doi:10.1093/annonc/mdw168

227. Gill DM, Hahn AW, Hale P, Maughan BL. Overview of current and future first-line systemic therapy for metastatic clear cell renal cell carcinoma. Curr Treat Options Oncol (2018) 19(1):6. doi:10.1007/s11864-018-0517-1

228. Chen Y, Liu YC, Sung YC, Ramjiawan RR, Lin TT, Chang CC, et al. Overcoming sorafenib evasion in hepatocellular carcinoma using CXCR4targeted nanoparticles to co-deliver MEK-inhibitors. Sci Rep (2017) 7:44123. doi:10.1038/srep44123

229. Huang Y, Goel S, Duda DG, Fukumura D, Jain RK. Vascular normalization as an emerging strategy to enhance cancer immunotherapy. Cancer Res (2013) 73(10):2943-8. doi:10.1158/0008-5472.CAN-12-4354

230. Huang Y, Yuan J, Righi E, Kamoun WS, Ancukiewicz M, Nezivar J, et al. Vascular normalizing doses of antiangiogenic treatment reprogram the immunosuppressive tumor microenvironment and enhance immunotherapy. Proc Natl Acad Sci U S A (2012) 109(43):17561-6. doi:10.1073/pnas. 1215397109

231. Shrimali RK, Yu Z, Theoret MR, Chinnasamy D, Restifo NP, Rosenberg SA. Antiangiogenic agents can increase lymphocyte infiltration into tumor and enhance the effectiveness of adoptive immunotherapy of cancer. Cancer Res (2010) 70(15):6171-80. doi:10.1158/0008-5472.CAN-10-0153

232. Hodi FS, Lawrence D, Lezcano C, Wu X, Zhou J, Sasada T, et al. Bevacizumab plus ipilimumab in patients with metastatic melanoma. Cancer Immunol Res (2014) 2(7):632-42. doi:10.1158/2326-6066.CIR-14-0053

233. Mendez-Huergo SP, Blidner AG, Rabinovich GA. Galectins: emerging regulatory checkpoints linking tumor immunity and angiogenesis. Curr Opin Immunol (2017) 45:8-15. doi:10.1016/j.coi.2016.12.003

234. Wu X, Giobbie-Hurder A, Liao X, Lawrence D, McDermott D, Zhou J, et al. VEGF neutralization plus CTLA-4 blockade alters soluble and cellular factors associated with enhancing lymphocyte infiltration and humoral recognition in melanoma. Cancer Immunol Res (2016) 4(10):858-68. doi:10.1158/23266066.CIR-16-0084

235. Wu X, Li J, Connolly EM, Liao X, Ouyang J, Giobbie-Hurder A, et al. Combined anti-VEGF and anti-CTLA-4 therapy elicits humoral immunity to galectin-1 which is associated with favorable clinical outcomes. Cancer Immunol Res (2017) 5(6):446-54. doi:10.1158/2326-6066.CIR-16-0385
236. Schmittnaegel M, Rigamonti N, Kadioglu E, Cassará A, Wyser Rmili C, Kiialainen A, et al. Dual angiopoietin-2 and VEGFA inhibition elicits antitumor immunity that is enhanced by PD-1 checkpoint blockade. Sci Transl Med (2017) 9(385):eaak9670. doi:10.1126/scitranslmed.aak9670

237. Allen E, Jabouille A, Rivera LB, Lodewijckx I, Missiaen R, Steri V, et al. Combined antiangiogenic and anti-PD-L1 therapy stimulates tumor immunity through HEV formation. Sci Transl Med (2017) 9(385):eaak9679. doi:10.1126/scitranslmed.aak9679

238. Guillerey C, Huntington ND, Smyth MJ. Targeting natural killer cells in cancer immunotherapy. Nat Immunol (2016) 17(9):1025-36. doi:10.1038/ ni.3518

239. Petty AJ, Yang Y. Tumor-associated macrophages: implications in cancer immunotherapy. Immunotherapy (2017) 9(3):289-302. doi:10.2217/imt2016-0135

240. De Henau O, Rausch M, Winkler D, Campesato LF, Liu C, Cymerman DH, et al. Overcoming resistance to checkpoint blockade therapy by targeting PI3Kgamma in myeloid cells. Nature (2016) 539(7629):443-7. doi:10.1038/ nature20554

241. Kaneda MM, Messer KS, Ralainirina N, Li H, Leem CJ, Gorjestani S, et al. PI3Kgamma is a molecular switch that controls immune suppression. Nature (2016) 539(7629):437-42. doi:10.1038/nature19834

242. Drew DA, Cao Y, Chan AT. Aspirin and colorectal cancer: the promise of precision chemoprevention. Nat Rev Cancer (2016) 16(3):173-86. doi:10.1038/ nrc.2016.4

243. Cuzick J, Thorat MA, Bosetti C, Brown PH, Burn J, Cook NR, et al. Estimates of benefits and harms of prophylactic use of aspirin in the general population. Ann Oncol (2015) 26(1):47-57. doi:10.1093/annonc/mdu225

244. Hamada T, Cao Y, Qian ZR, Masugi Y, Nowak JA, Yang J, et al. Aspirin use and colorectal cancer survival according to tumor CD274 (programmed cell death 1 ligand 1) expression status. J Clin Oncol (2017) 35(16):1836-44. doi:10.1200/JCO.2016.70.7547

245. Zelenay S, van der Veen AG, Böttcher JP, Snelgrove KJ, Rogers N, Acton SE, et al. Cyclooxygenase-dependent tumor growth through evasion of immunity. Cell (2015) 162(6):1257-70. doi:10.1016/j.cell.2015.08.015

246. Albini A, DeCensi A, Cavalli F, Costa A. Cancer prevention and interception: a new era for chemopreventive approaches. Clin Cancer Res (2016) 22(17):4322-7. doi:10.1158/1078-0432.CCR-16-0695

247. Talarico G, Orecchioni S, Dallaglio K, Reggiani F, Mancuso P, Calleri A, et al. Aspirin and atenolol enhance metformin activity against breast cancer by targeting both neoplastic and microenvironment cells. Sci Rep (2016) 6:18673. doi:10.1038/srep18673

248. Albini A, Bassani B, Baci D, Dallaglio K, Gallazzi M, Corradino P, et al. Nutraceuticals and "repurposed" drugs of phytochemical origin in prevention and interception of chronic degenerative disease and cancer. Curr Med Chem (2018). doi:10.2174/0929867324666170920144130

249. Dallaglio K, Bruno A, Cantelmo AR, Esposito AI, Ruggiero L, Orecchioni S, et al. Paradoxic effects of metformin on endothelial cells and angiogenesis. Carcinogenesis (2014) 35(5):1055-66. doi:10.1093/carcin/bgu001

250. Orecchioni S, Reggiani F, Talarico G, Mancuso P, Calleri A, Gregato G, et al. The biguanides metformin and phenformin inhibit angiogenesis, local and metastatic growth of breast cancer by targeting both neoplastic and microenvironment cells. Int J Cancer (2015) 136(6):E534-44. doi:10.1002/ ijc. 29193

251. Pollak M. The effects of metformin on gut microbiota and the immune system as research frontiers. Diabetologia (2017) 60(9):1662-7. doi:10.1007/ s00125-017-4352-x

252. Eikawa S, Nishida M, Mizukami S, Yamazaki C, Nakayama E, Udono H. Immune-mediated antitumor effect by type 2 diabetes drug, metformin. Proc Natl Acad Sci U S A (2015) 112(6):1809-14. doi:10.1073/pnas. 1417636112

253. Ball MS, Shipman EP, Kim H, Liby KT, Pioli PA. CDDO-Me redirects activation of breast tumor associated macrophages. PLoS One (2016) 11(2):e0149600. doi:10.1371/journal.pone.0149600

254. Fitzpatrick LR, Stonesifer E, Small JS, Liby KT. The synthetic triterpenoid (CDDO-Im) inhibits STAT3, as well as IL-17, and improves DSS-induced colitis in mice. Inflammopharmacology (2014) 22(6):341-9. doi:10.1007/ s10787-014-0203-2

255. Leal AS, Sporn MB, Pioli PA, Liby KT. The triterpenoid CDDOimidazolide reduces immune cell infiltration and cytokine secretion in the 
KrasG12D;Pdx1-Cre (KC) mouse model of pancreatic cancer. Carcinogenesis (2016) 37(12):1170-9. doi:10.1093/carcin/bgw099

256. Benelli R, Venè R, Ciarlo M, Carlone S, Barbieri O, Ferrari N, et al. The AKT/ NF-kappaB inhibitor xanthohumol is a potent anti-lymphocytic leukemia drug overcoming chemoresistance and cell infiltration. Biochem Pharmacol (2012) 83(12):1634-42. doi:10.1016/j.bcp.2012.03.006

257. Dell'Eva R, Ambrosini C, Vannini N, Piaggio G, Albini A, Ferrari N. AKT/ NF-kappaB inhibitor xanthohumol targets cell growth and angiogenesis in hematologic malignancies. Cancer (2007) 110(9):2007-11. doi:10.1002/ cncr. 23017

258. Lust S, Vanhoecke B, Janssens A, Philippe J, Bracke M, Offner F. Xanthohumol kills B-chronic lymphocytic leukemia cells by an apoptotic mechanism. Mol Nutr Food Res (2005) 49(9):844-50. doi:10.1002/mnfr.200500045

259. Monteghirfo S, Tosetti F, Ambrosini C, Stigliani S, Pozzi S, Frassoni F, et al. Antileukemia effects of xanthohumol in Bcr/Abl-transformed cells involve nuclear factor-kappaB and p53 modulation. Mol Cancer Ther (2008) 7(9):2692-702. doi:10.1158/1535-7163.MCT-08-0132

260. Zhang W, Pan Y, Gou P, Zhou C, Ma L, Liu Q, et al. Effect of xanthohumol on Th1/Th2 balance in a breast cancer mouse model. Oncol Rep (2018) 39(1):280-8. doi:10.3892/or.2017.6094

261. Jang JY, Lee JK, Jeon YK, Kim CW. Exosome derived from epigallocatechin gallate treated breast cancer cells suppresses tumor growth by inhibiting tumor-associated macrophage infiltration and M2 polarization. BMC Cancer (2013) 13:421. doi:10.1186/1471-2407-13-421
262. Mukherjee S, Baidoo JNE, Sampat S, Mancuso A, David L, Cohen LS, et al. Liposomal TriCurin, a synergistic combination of curcumin, epicatechin gallate and resveratrol, repolarizes tumor-associated microglia/macrophages, and eliminates glioblastoma (GBM) and GBM stem cells. Molecules (2018) 23(1):E201. doi:10.3390/molecules23010201

263. Ferrari N, Tosetti F, De Flora S, Donatelli F, Sogno I, Noonan DM, et al. Diet-derived phytochemicals: from cancer chemoprevention to cardiooncological prevention. Curr Drug Targets (2011) 12(13):1909-24. doi:10.2174/ 138945011798184227

264. Albini A, Pennesi G, Donatelli F, Cammarota R, De Flora S, Noonan DM. Cardiotoxicity of anticancer drugs: the need for cardio-oncology and cardio-oncological prevention. J Natl Cancer Inst (2010) 102(1):14-25. doi:10.1093/ jnci/djp440

Conflict of Interest Statement: The authors declare that the research was conducted in the absence of any commercial or financial relationships that could be construed as a potential conflict of interest.

Copyright $\odot 2018$ Albini, Bruno, Noonan and Mortara. This is an open-access article distributed under the terms of the Creative Commons Attribution License (CC BY). The use, distribution or reproduction in other forums is permitted, provided the original author(s) and the copyright owner are credited and that the original publication in this journal is cited, in accordance with accepted academic practice. No use, distribution or reproduction is permitted which does not comply with these terms. 